\title{
Between Photocatalysis and Photosynthesis: Synchrotron spectroscopy methods on molecules and materials for solar hydrogen generation
}

Debajeet K. Bora ${ }^{1,2,3}$, Yelin $\mathrm{Hu}^{1,4}$, Sebastian Thiess ${ }^{5}$, Selma Erat ${ }^{1,6}$, Xuefei Feng ${ }^{3,7}$, Sumanta Mukherjee ${ }^{8}$, Giuseppino Fortunato ${ }^{9}$, Nicolas Gaillard ${ }^{10}$, Rita Toth $^{1}$, Krisztina Gajda-Schrantz ${ }^{1,11}$,Wolfgang Drube ${ }^{5}$, Michael Grätzel ${ }^{4}$, Jinghua Guo ${ }^{3}$, Junfa Zhu ${ }^{7}$, Edwin C. Constable ${ }^{2}$, D.D. Sarma ${ }^{8,12}$, Hongxin Wang ${ }^{13,14}$, Artur Braun ${ }^{1 *}$

\section{${ }^{1}$ Laboratory for High Performance Ceramics}

Empa. Swiss Federal Laboratories for Materials Science \& Technology CH - 8600 Dübendorf, Switzerland

${ }^{2}$ Department of Chemistry, University of Basel, CH-4052 Basel, Switzerland

${ }^{3}$ Advanced Light Source, Lawrence Berkeley National Laboratory Berkeley CA 94720, United States

${ }^{4}$ Laboratory for Photonics \& Interfaces, Ecole Polytechnique Federale de Lausanne CH-1005 Lausanne, Switzerland

${ }^{5}$ Deutsches Elektronen-Synchrotron DESY, D-22603 Hamburg, Germany

${ }^{6}$ Toros University, Faculty of Engineering, Electrical-Electronics Department, TR - 33140, Mersin, Turkey

${ }^{7}$ National Synchrotron Radiation Laboratory, University of Science and Technology of China, Hefei, 230029, China 
J. Electron Spectroscopy and Related Phenomena:

Special Issue on The Spectroscopy of Energy Materials, submission deadline 31. August 2012

${ }^{8}$ Solid State and Structural Chemistry Unit, Indian Institute of Science Bangalore 560012, India

${ }^{9}$ Laboratory of Advanced Fibers

Empa, Swiss Federal Laboratories for Materials Science and Technology,

CH- 9014 St. Gallen, Switzerland

${ }^{10}$ Hawaii Natural Energy Institute, University of Hawaii at Manoa Honolulu HI 96822, United States

${ }^{11}$ Environmental Chemistry Research Group, Department of Inorganic and Analytical Chemistry, Szeged University, H-6720 Szeged, Hungary

${ }^{12}$ Council of Scientific and Industrial Research - Network of Institutes for Solar Energy (CSIR-NISE), New Delhi, India

${ }^{13}$ Physical Biosciences Division, Lawrence Berkeley National Laboratory Berkeley CA 94720, United States

${ }^{14}$ Chemistry Department, University of California Davis, One Shields Ave., Davis CA 95616, United States 


\begin{abstract}
Energy research is to a large extent materials research, encompassing the physics and chemistry of materials, including their synthesis, processing towards components and design towards architectures, allowing for their functionality as energy devices, extending towards their operation parameters and environment, including also their degradation, limited life, ultimate failure and potential recycling. In all these stages, $x-$ ray and electron spectroscopy are helpful methods for analysis, characterization and diagnostics for the engineer and for the researcher working in basic science. This paper gives a short overview of experiments with x-ray and electron spectroscopy for solar energy and water splitting materials and addresses also the issue of solar fuel, a relatively new topic in energy research. The featured systems are iron oxide and tungsten oxide as photoanodes, and hydrogenases as molecular systems. We present surface and sub-surface studies with ambient pressure XPS and hard x-ray XPS, resonant photoemission, light induced effects in resonant photoemission experiments and a photo-electrochemical in-situ/operando experiment, and nuclear resonant vibrational spectroscopy (NRVS).
\end{abstract}

\title{
Keywords
}

NEXAFS; VB-PES; photoelectrochemistry; artificial photosynthesis; valence band; hole doping; charge transfer; solar fuels; solar hydrogen; photocatalysis; resonant photoemission; photo-electrochemistry; x-ray absorption; RIXS; HAX-PES; AP-XPS; NRVS; surface defects; bulk defects; hydrogenase; hematite; tungsten oxide; water splitting 


\section{Introduction}

From solar hydrogen to solar fuels is still a long way to go. The analogies of photocatalysis and photoelectrochemistry are quite strong [1]. This paper provides a broad summary of past, ongoing and potential future experimental work related to solar fuels.

Our sun is the world's principal energy source and all renewable energy sources can be traced back to the solar energy. Our fossil fuels were formed by solar energy via photosynthesis (PS), and our biomass derived from plants originates from photosynthesis. Photovoltaic (PV) is the direct conversion of solar energy into electricity and utilizes semiconductors, which generate electron-hole pairs upon illumination with visible light which drive electric power in solar cells.

The circumstance that solar cells in principle can work only during sunshine (daylight) and that electricity needs to be stored in order to be available at some later time, poses a general shortcoming for PV in an energy economy, notwithstanding that $\mathrm{PV}$ is an economically successful energy technology. The storage of electricity is done by batteries and capacitors and will not be covered here, notwithstanding that most techniques demonstrated here are also applicable to battery and capacitor research.

Sunlight can be used to generate hydrogen by solar water splitting in photoelectrochemical cells (PEC) [2]. Hydrogen can be considered the chemically most simple solar fuel. Major part of the studies shown here will relate to PEC materials. Since the storage of hydrogen is a socio-economic unresolved issue, there is a desire to produce liquid solar fuels, which practically will have to be hydrocarbons. Current ideas center on the sequestering of $\mathrm{CO}_{2}$, and the use of $\mathrm{CO}_{2}$ and $\mathrm{H}_{2} \mathrm{O}$ and solar energy to synthesize easy to use, store and transport hydrocarbons as solar fuels. 
Consequently, these efforts can be summarized under the term "artificial photosynthesis" (AP). The study of the naturally occurring photosynthesis, which has been awarded with the Nobel Prize in Chemistry in 1961 to Melvin Calvin, shows us that not just "materials", but molecular machinery and architectures are required to synthesize hydrocarbons (solar fuels) from water, carbon dioxide and sunlight. At least this is the way how nature manages these fascinating tasks. AP technology is still in its infancy. Researchers worldwide are struggling to finding a simple affordable concept for $\mathrm{H}_{2}$ production by solar water splitting. Hence, little literature covering $\mathrm{x}$-ray and photoelectron spectroscopy on this topic is available, although for example hard x-ray spectroscopy work is increasingly emerging, see for example [3]. Yet, x-ray and electron spectroscopy has been very material in understanding specific issues in photosynthesis, in particular protein spectroscopy on protein and protein models and motifs, see for example [4]. This paper is outlined as follows. We begin with photocatalysis by semiconducting metal oxides and show how the structure of such oxides changes with doping and substitution and how the metal L-edges and oxygen or nitrogen K-edges evolve accordingly. We then extend towards the principles of photocatalytic water splitting in photoelectrochemical cells (PEC) and present studies on the electronic structure of prominent PEC photoanode materials, tungsten oxide and iron oxide, with oxygen K-edge and valence band photoemission spectroscopy. We then move on to very recent in-situ NEXAFS and XPS studies where the metal oxides are in contact with liquid electrolytes or gases and exposed to visible light. Then, we discuss protein spectroscopy and show an iron L-edge spectrum of synthetic hydrogenase supported with atomic multiplett simulation. Finally, we show ${ }^{57} \mathrm{Fe}$ element-specific nuclear resonant vibration spectroscopy on hydrogenase. 


\section{Photocatalysis}

Biofuels will most likely be produced by some sort of photosynthesis, a process which by common terms is not considered very efficient. Yet, mankind has not yet mastered this process with technology, which is called artificial photosynthesis (AP) and basically constitutes production of organic matter from $\mathrm{H}_{2} \mathrm{O}$ and $\mathrm{CO}_{2}$. It is instructive, however, to begin with photocatalysis (PC), which is used to decompose organic contaminants in waste water, and is so to speak the opposite of photosynthesis.

PC is based on electron-hole pair generation in semiconductors upon exposure to UV light. $\mathrm{TiO}_{2}$ is a well-studied high performance $\mathrm{PC}$ material, but its $3.1 \mathrm{eV}$ band gap energy makes that $\mathrm{TiO}_{2}$ requires highly energetic UV light for operation, rendering it impractical for daylight applications. Therefore, great efforts focus on band gap tailoring by substitution and doping on the cationic and anionic side [5].
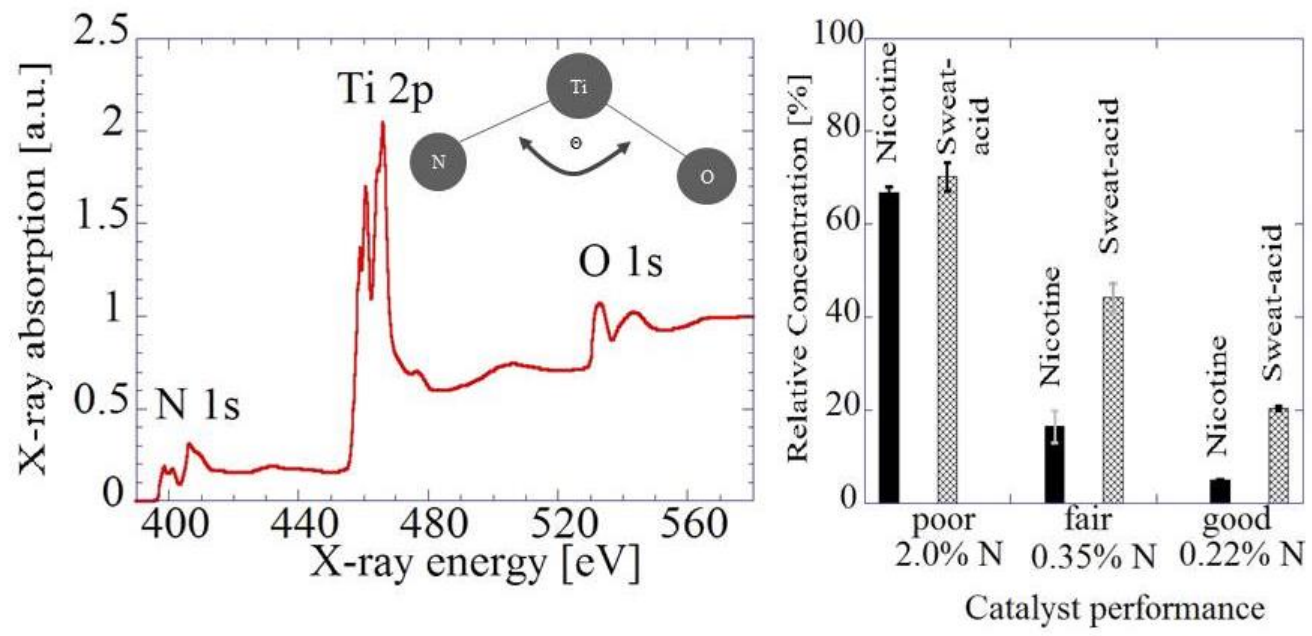

Figure 1: Left - NEXAFS spectrum obtained from a full scan of $\mathrm{TiN}_{0.1} \mathrm{O}_{1.9}$ covering the $\mathrm{N} 1 \mathrm{~s}$, Ti2p and $\mathrm{O} 1 \mathrm{~s}$ regions. The scan covers the complete $\mathrm{N}-\mathrm{Ti}-\mathrm{O}$ superexchange unit. Right - Comparison of the photocatalytic performance of $\mathrm{TiO} 2$ doped with different $\%$ or nitrogen. 
Figure 1 shows the near-edge x-ray absorption fine structure (NEXAFS) spectrum of $5 \%$ nitrogen doped titanium oxide $\mathrm{TiN}_{0.1} \mathrm{O}_{1.9}$ covering the x-ray $\mathrm{K}$-shell absorption edges of nitrogen $(390 \mathrm{eV}-440 \mathrm{eV})$ and oxygen $(525 \mathrm{eV}-560 \mathrm{eV})$, and the Ti2p doublet (L3,2 edge $410 \mathrm{eV}-500 \mathrm{eV}$ ). This is one of the cases where the complete superexchange unit of a doped material (N-Ti-O) can be probed with one single NEXAFS scan. The anion edges probe the valence band with the Ti3d-O2p and Ti3d$\mathrm{N} 2 \mathrm{p}$ hybridized states with the more or less well developed $\mathrm{t}_{2 \mathrm{~g}}-\mathrm{e}_{\mathrm{g}}$ doublets.

It is unfortunate that nitrogen doping improves the photocatalytic activity of $\mathrm{TiO}_{2}$ only up to a level of say $0.2 \%$ nitrogen [5], and we hence can probe $\mathrm{N}$ only for the pathologic cases with higher $\mathrm{N}$ substitution. The right panel in Figure 1 compares the decomposition power of $\mathrm{TiO}_{2}$ doped with various $\mathrm{N}$ concentrations and shows that the PC with higher $\mathrm{N}$ concentrations cannot decompose so well organics such as sweat acid or nicotine, which are given on the
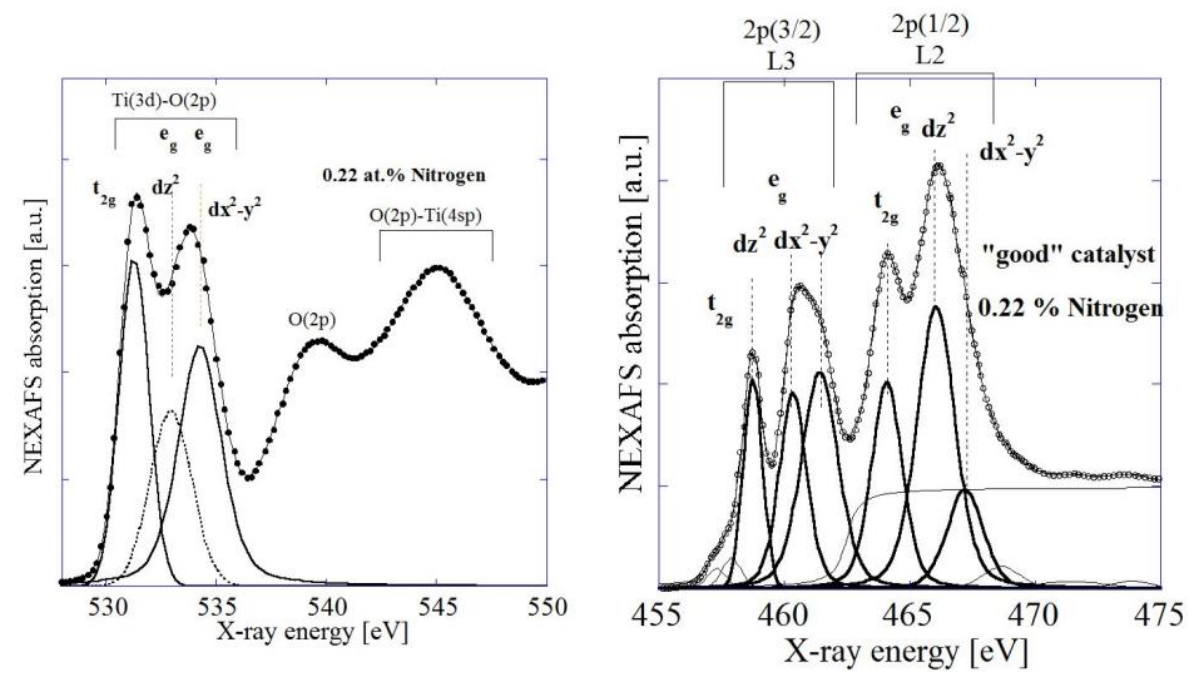

Figure 2: Left - Oxygen K-edge spectrum of the well working $0.22 \%$ nitrogen doped $\mathrm{TiO}_{2}$ photocatalyst. Right - NEXAFS L-edge spectrum of the same sample with peak deconvolution and spectral assignment. Compare [6]. 
Figure 2 shows the O K-edge and Ti L-edge NEXAFS spectra of $0.22 \%$ nitrogen doped titanium oxide. While the $\mathrm{N}$ spectrum of this sample could not be resolved, we notice differences in the oxygen and titanium spectra which are caused by the nitrogen doping. In particular we can identify a new state between the $t_{2 g}$ and $e_{g}$ doublet which becomes apparent upon direct comparison with the oxygen spectrum from a non-doped $\mathrm{TiO}_{2}$ single crystal. These doping induced structural changes cause also significant changes in the Ti L-edge spectra [6].

While slight doping can narrow the band gap and make the photocatalyst absorbing a larger portion of the visible part of the spectrum, extensive doping (or wrong doping, see for example [7]) causes structural deformation and defects, as visible from the extra peak between the $\mathrm{t}_{2 \mathrm{~g}} / \mathrm{e}_{\mathrm{g}}$ states in the $\mathrm{TiO}_{2}$ doublet. Such defects act as recombination centers for electrons and holes and can work against the necessary transport of holes to the semiconductor surface where it is supposed to decompose organics. 


\section{Water splitting in photoelectrochemical cells}

Electrolysis of water requires a thermodynamic potential of at least 1.23 Volt between the electrodes in aqueous electrolytes. Water splitting in photoelectrochemical cells was demonstrated by Fujishima and Honda over 40 years ago [8], with a $\mathrm{TiO}_{2}$ photoanode exposed to UV radiation. The experimental principle is schematized in Figure 3. When a semiconductor is struck by light, electron-hole pairs are generated. At the photoanode, for example $\alpha-\mathrm{Fe}_{2} \mathrm{O}_{3}$, the photo hole diffuses to the metal oxide surface and oxidizes water to evolve oxygen.
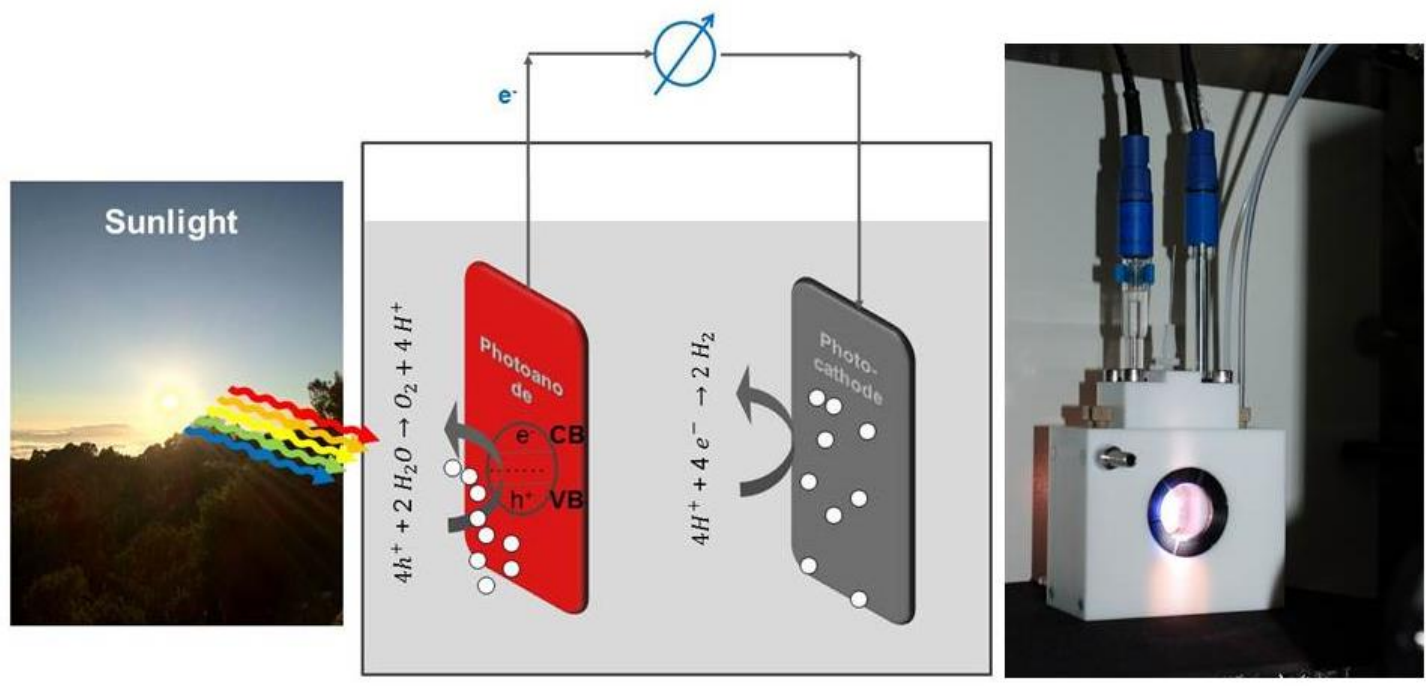

Figure 3: Left - Schematic of a photo-electrochemical cell for solar water splitting with photoanode (left) and photocathode (right) inserted in aqueous electrolyte, such as 1 molar $\mathrm{KOH}$. Right - PEC cell from Teflon with inserted hematite anode.

The photo electron migrates to the current collector. At the counter electrode, which can be a metal electrode or a photo cathode like $\mathrm{Cu}_{2} \mathrm{O}$, the electron diffuses to the electrode surface and reduces protons in the electrolyte to evolve hydrogen.

Figure 4 shows a PEC test station with solar simulator light source, a potentiostat with impedance analyzer (Voltalab80 by Radiometer Analytical) connected to a gas chromatograph (Shimadzu GC-2014) for hydrogen quantification, and the PEC cell 
filled with $1 \mathrm{M} \mathrm{KOH}$, with a Si doped hematite photoanode with cobalt co-catalyst, $\mathrm{Pt}$ counter electrode and $\mathrm{Ag} / \mathrm{AgCl}$ reference electrode. Typically, the photocurrent as a function of applied voltage is measured in order to assess a photoelectrode. Additionally, cyclic voltamograms (CV) provide information about RedOx processes and double layer capacity, and impedance spectroscopy (IS) provides information about charge carrier dynamics [9].
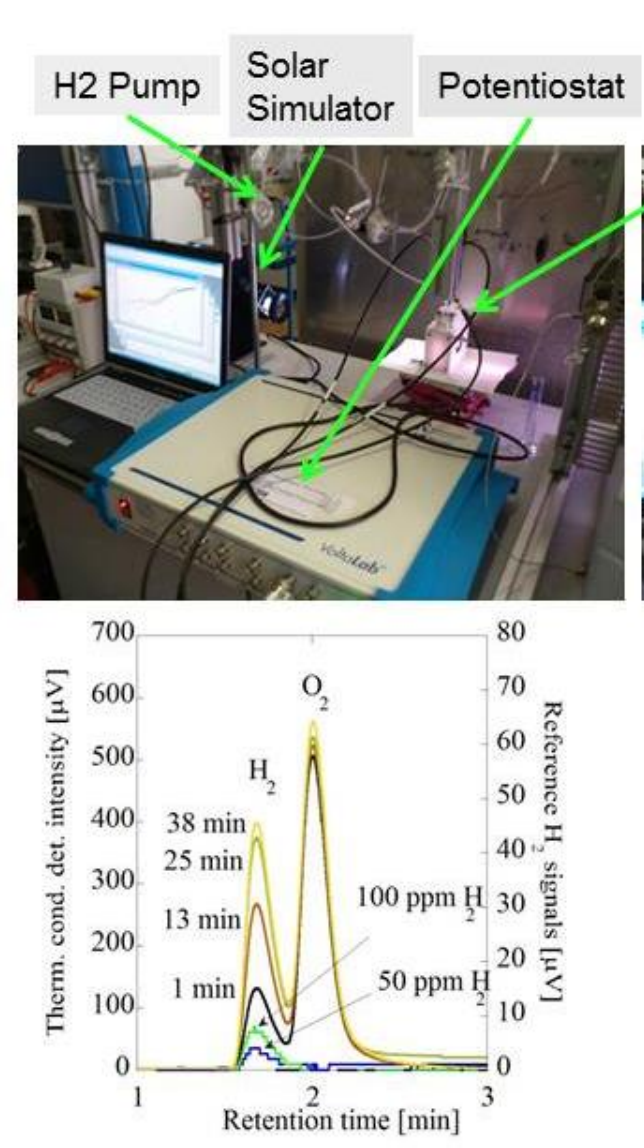
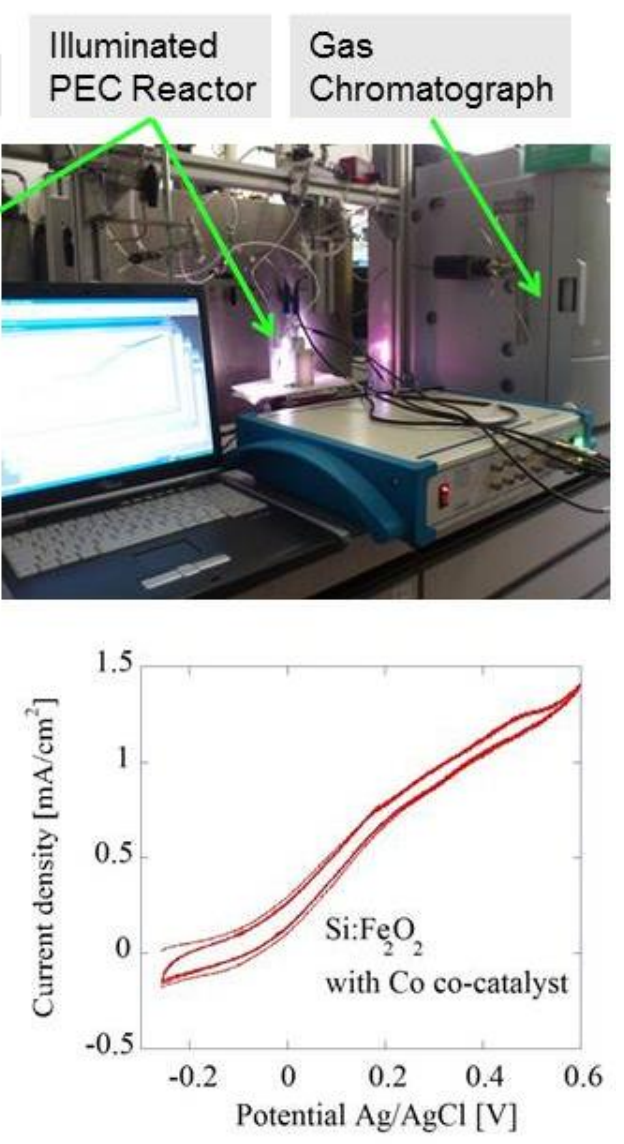

Figure 4: Top - PEC test station for solar hydrogen generation and detection at Empa.

Bottom - $\mathrm{H}_{2}$ Chromatograms and $\mathrm{CV}$ recorded during 30 min of $\mathrm{H}_{2}$ generation from $1 \% \mathrm{Si}$-doped $\alpha-\mathrm{Fe}_{2} \mathrm{O}_{3}$ with sub-monolayer of cobalt co-catalyst.

Certainly, the evolved hydrogen during PEC operation is an important measure. The generated $\mathrm{H}_{2}$ is recirculated with argon carrier gas by a pump at 0.1 bar pressure, 
J. Electron Spectroscopy and Related Phenomena:

Special Issue on The Spectroscopy of Energy Materials, submission deadline 31. August 2012

enabling us to monitor $\mathrm{H}_{2}$ evolution online. For calibration two reference gases containing 50 and $100 \mathrm{ppm} \mathrm{H}_{2}$ in argon are used. $10 \mu \mathrm{L}$ samples of the headspace are injected at 1, 13, 25 and 38 minutes (Figure 4). This is already a complex experimental setup and it would be inspirational to combine this operando with $\mathrm{x}$-ray or electron spectroscopy.

For efficient conversion of solar light into electrical (PV) or chemical energy, as much as possible solar energy should be absorbed by the semiconductor, which requires a particular optical band gap. $\mathrm{TiO}_{2}$ with $3.1 \mathrm{eV}$ bandgap absorbs only ultraviolet radiation and can be ruled out for daylight applications. In addition, the conduction band of the semiconductor must be energetically located so that it can oxidize water. Not all semiconductors satisfy this condition and thus need a bias potential [10]. The width of the band gap is also a measure of the chemical bond strength. Semiconductors stable under illumination (typically oxides of metals such as titanium) therefore have a wide band gap [11].

\section{Surface and sub-surface studies on tungsten and iron oxide photo anodes}

- In-situ XPS on $W_{3-\delta} P L D$ films at high temperature and high oxygen pressure Tungsten oxide is a semiconductor with around $2.7 \mathrm{eV}$ band gap. Stoichiometric tungsten oxide $\mathrm{WO}_{3}$ has yellow color and absorbs a large part of the visible solar spectrum. It is suited as photoanode particularly in seawater [12]. Synthesis typically yields sub-stoichiometric tungsten oxide $\mathrm{WO}_{3-\delta}$ with metal conductivity and blue color from oxygen vacancies and requires subsequent oxidative treatment. These vacancies constitute electronic defect states which are visible as up to six convoluted peaks near the Fermi energy in valence band XPS or PES spectra [13-15]. $\mathrm{WO}_{3-\delta}$ with 
metal conductivity cannot produce the necessary electron hole pairs for solar energy conversion.

Therefore, understanding of the process conditions that convert metal conducting to semiconducting behavior is important. Oxidative and reductive processing of metal oxides such as $\mathrm{TiO}_{2}$ certainly has impact on the electronic structure, which can be measured for example with NEXAFS spectroscopy [16]. Thermal oxidation of a 125 $\mathrm{nm}$ thick pulsed laser deposited blue, non-stoichiometric $\mathrm{WO}_{3-\delta}$ film turns the color from blue to yellow [13]. The resonant valence band photoemission spectra (VB-PES) of the as-deposited blue film and oxidized yellow film (ALS BL 9.3.2) suggests that a defect state near the Fermi energy originates from the non-stoichiometry, i.e. oxygen deficiency and constitutes insofar electronic defect states which can be partially eliminated by heat treatment in oxygen (Figure 5 left).
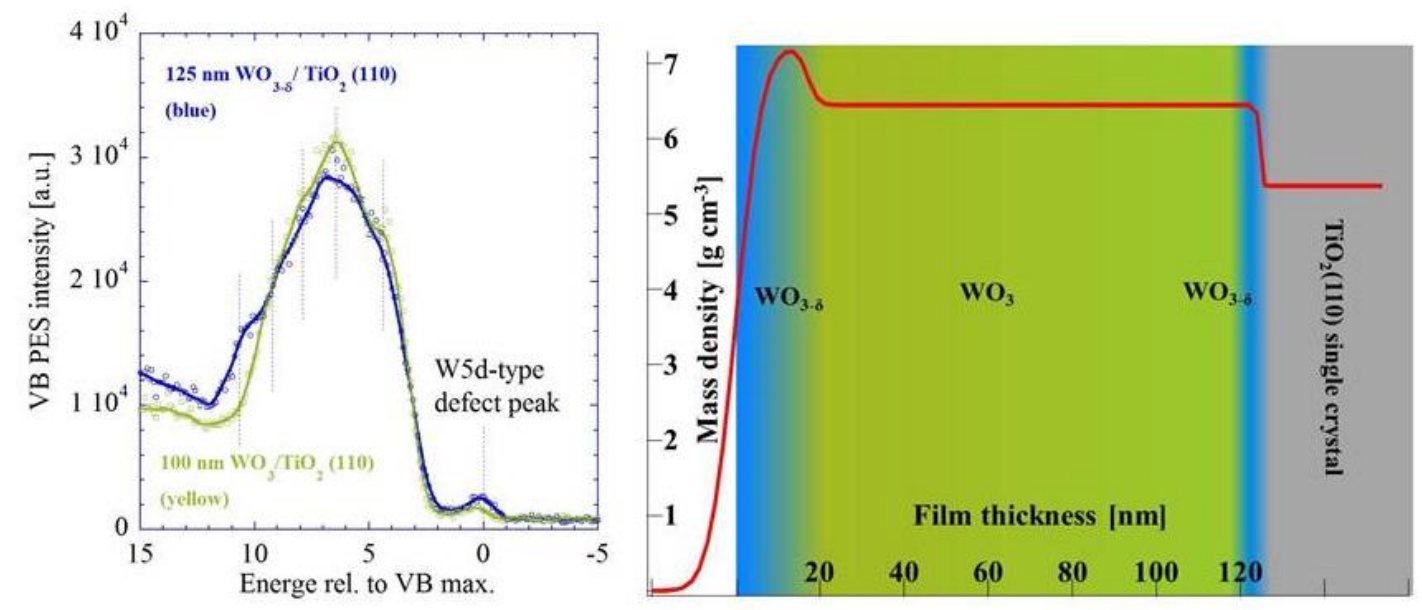

Figure 5: Left - VB PES spectra of $125 \mathrm{~nm}$ thick blue (as deposited) and yellow (oxidized) tungsten oxide films obtained with $\mathrm{E}_{0}=700 \mathrm{eV}$. The W5d defect peak intensity decreases upon oxidation. Right - Schematic of film deposited on $\mathrm{TiO}_{2}$ (110), with overlaid density profile from X-ray reflectometry. 
The defects of the as-deposited blue film are located throughout the film. Thermal oxidation heals the defects in the bulk, but residual defect states remain at the filmsubstrate interface, possibly due to interfacial strain, as indicated in Figure 5 (right), and at the top surface.

Nominally $10 \mathrm{~nm}$ sub-stoichiometric films deposited on substrates with (001) and (110) orientation show also defect states near the Fermi energy in the VB x-ray photoelectron spectra (XPS) [17]. The spectral weight of the defect states is particularly strong for the film grown on the (001) surface (Figure 6 left). in-situ XPS under oxygen pressures of 100 mTorr (BL 9.3.2, ALS) shows that the spectral weight of defect states decreases significantly at $500 \mathrm{~K}$ for the film on the (110) substrate (Figure 6 right), whereas that of the film grown on the (001) substrate remain the same up to $673 \mathrm{~K}$. Quantitative analysis of the oxygen 1s core level XPS spectra shows that chemisorbed water from sample storage under ambient conditions is desorbed during heating in $\mathrm{O}_{2}$ [17].
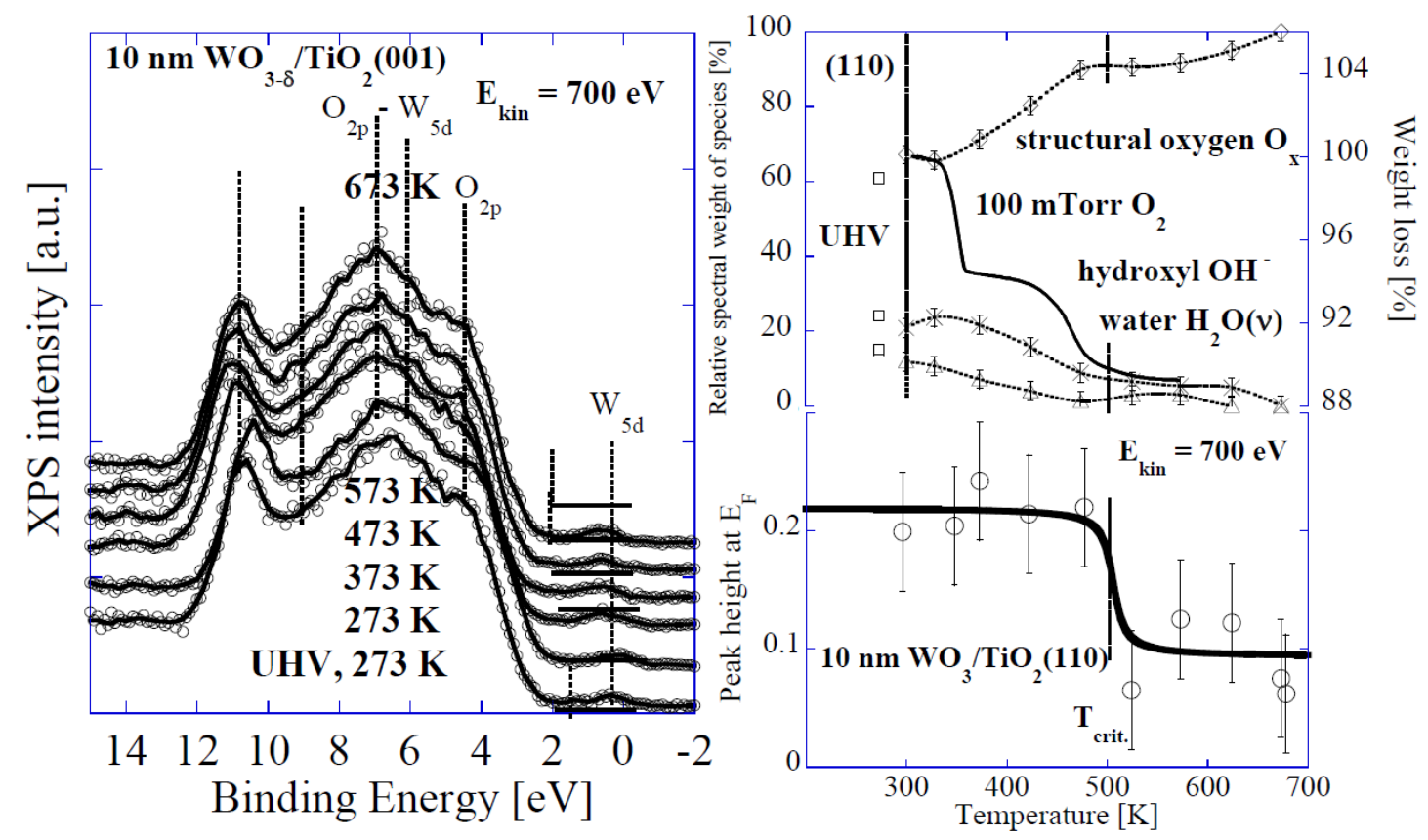

Figure 6: Left - VB PES spectra of $10 \mathrm{~nm}$ thin $\mathrm{WO}_{3-\delta}$ films grown on $\mathrm{TiO}_{2}(001)$ heated in 100 mTorr oxygen up to $673 \mathrm{~K}$, showing that the defect states persist 
J. Electron Spectroscopy and Related Phenomena:

Special Issue on The Spectroscopy of Energy Materials, submission deadline 31. August 2012

throughout the heating in oxygen. Right - Evolution of structural oxygen, hydroxyl and water signatures in $\mathrm{WO}_{3-\delta}$ grown on $\mathrm{TiO}_{2}(110)$ during heating in $\mathrm{O}_{2}$. The bottom panel shows how the defect state peak height decreases at $500 \mathrm{~K}$.

Furthermore, diffusion of Ti from the substrate to the film surface is observed with the (110) substrate, as was evidenced by sudden appearance of the Ti $2 \mathrm{p}$ core level signature between $623 \mathrm{~K}$ and $673 \mathrm{~K}$ [17]. The film grown on the (001) surface does not show such inter-diffusion, which suggests that the orientation of the substrate can have drastic influence on the high temperature integrity of the tungsten oxide films: a technologically important issue for heterostructure photoelectrode assemblies.

Looking back to the previous section, we remember that electron hole pairs are generated in the bulk of the material throughout the range where the absorption of photons with relevant energy takes place. And the surface and subsurface can significantly differ from the bulk.

Hence, conventional surface sensitive XPS does not necessarily probe the sample depth regions characteristic for device functionality. However, the tunability of the mean escape depth of photoelectrons in photoemission allows determination the profile of various species non-destructive as a function of the depth from the surface $[18,19]$ and study the interface structure of aforementioned films. Use of hard X-rays with energies of several $\mathrm{keV}$ not only allows to access deeper core levels but also produces photoelectrons with high kinetic energies and correspondingly larger inelastic mean free paths. Combination of high brilliance synchrotron X-ray sources and efficient detection techniques for energetic electrons makes it possible to vary the effective escape depth $\left(\lambda_{\text {eff }}\right)$ up to some ten nanometer and the elegance of this technique has already been proven in many contexts [20-24]. We have therefore 
performed HAXPES measurements on the as-despoited oxygen deficient and on one subsequently oxidized $\mathrm{WO}_{3}$ films grown on a $\mathrm{TiO}_{2}$ substrate to investigate the chemical composition across the film and at the interfaces and the effect of the annealing. The experiments were performed using the HAXPES instrument at undulator beamline P09 of PETRA III (DESY, Germany [25]).

Figure 7 shows the spectra obtained for $\mathrm{W} 4 \mathrm{~d}$ and $\mathrm{Ti} 2 \mathrm{p}$ (inset) at three different photon energies from $4500 \mathrm{eV}$ to highly bulk sensitive $8000 \mathrm{eV}$ for the oxidized yellow (A) and the as-deposited blue films (B). The position of the Ti $2 \mathrm{p}$ peaks obtained at $458.5 \mathrm{eV}$ and at $464.2 \mathrm{eV}$ with a characteristic spin orbit separation of 5.7 eV is easily associated with $\mathrm{Ti}^{4+}$ in $\mathrm{TiO}_{2}$. The $\mathrm{W} 4 \mathrm{~d}$ peaks of $\mathrm{WO}_{3}$ are measured at $247.1 \mathrm{eV}$ and $259.5 \mathrm{eV}$ with a spin orbit separation of $12.4 \mathrm{eV}$.

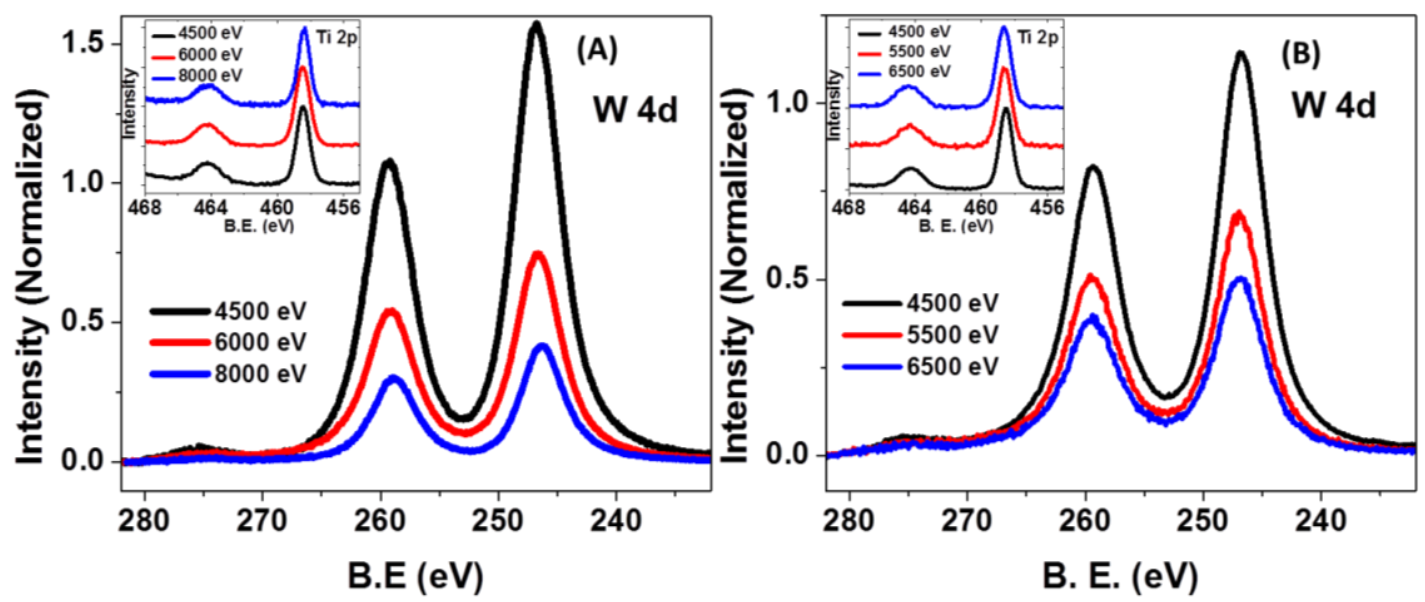

Figure 7: Photoemission spectra of $\mathrm{W} 4 \mathrm{~d}$ and $\mathrm{Ti} 2 \mathrm{p}$ (inset) core levels obtained at three different photon energies from the annealed yellow sample (A) and the unannealed blue sample (B). The $\mathrm{W} 4 \mathrm{~d}$ spectra are normalized with respect to the intensity of the $\mathrm{Ti} 2 \mathrm{p}$ core levels obtained at the same energy.

The sharp peak shape obtained at all different photon energies clearly indicates the presence of only one kind of oxide species for both $\mathrm{W}$ and $\mathrm{Ti}$ in these samples. To 
J. Electron Spectroscopy and Related Phenomena:

Special Issue on The Spectroscopy of Energy Materials, submission deadline 31. August 2012

compare the intensity ratios of these two core levels, we normalized all spectra with their corresponding photo ionization cross sections [24]. The $\mathrm{W} 4 \mathrm{~d}$ peaks were then normalized relative to the intensity of the $\mathrm{Ti} 2 \mathrm{p}$ core levels at those photon energies shown in Figure 7 A (annealed sample) and B (un-annealed sample). For both samples, the normalized $\mathrm{W} 4 \mathrm{~d}$ intensity decreases with increasing photon energy because $\mathrm{WO}_{3}$ is on top of $\mathrm{TiO}_{2}$, and with increasing photon energy we are probing more of the $\mathrm{TiO}_{2}$ layer across the interface. We have estimated the thickness of the $\mathrm{WO}_{3}$ layer by fitting $[18,19,22]$ the intensity ratio variation yielding a thickness around $12 \mathrm{~nm}$ for the oxidized film. Besides this, no changes of the peak profiles are observed, which is indicative of a homogeneous chemical composition throughout the layer. This suggests presence of a sharp $\mathrm{WO}_{3}-\mathrm{TiO}_{2}$ interface in this thin film which was not affected by the annealing in $\mathrm{O}_{2}$.

\section{- XPS on copper tungstate sprayed films}

Substitution of $\mathrm{WO}_{3}$ with $\mathrm{Cu}$ at around $800^{\circ} \mathrm{C}$ forms the compound $\mathrm{CuWO}_{4}$, which has a smaller band gap than $\mathrm{WO}_{3}$ and thus absorbs even more of the visible solar spectrum [25]. But also here proper synthesis and processing conditions determine the suitability of the material. Figure 8 shows the XPS valence band (VB) spectra of sprayed $\mathrm{CuWO}_{4-\delta}$ films heat treated under $0 \%, 10 \%$, and $50 \%$ oxygen concentration below $800^{\circ} \mathrm{C}$. 

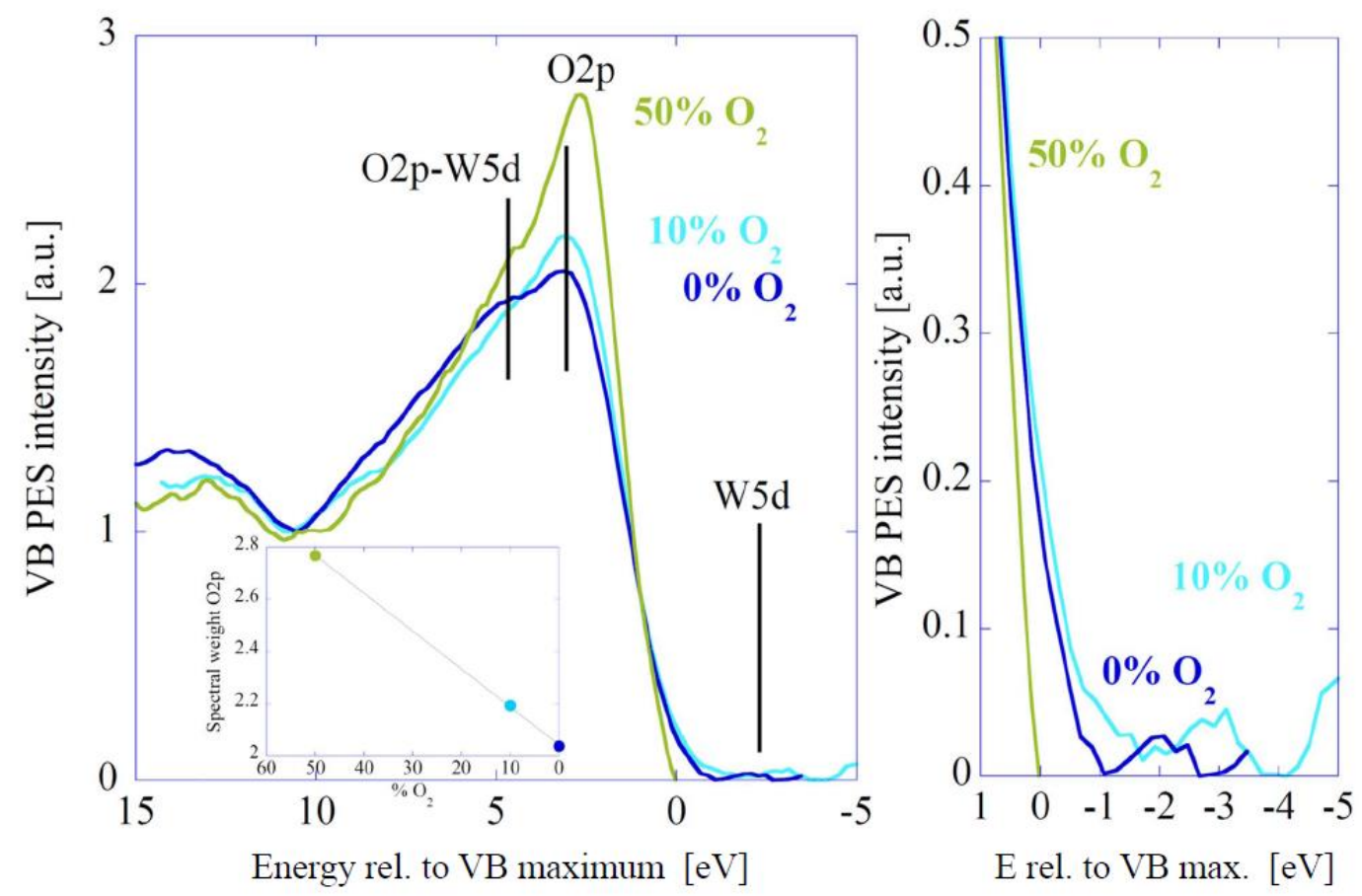

Figure 8: XPS valence band spectra of sprayed deposited $\mathrm{CuWO}_{4-\delta}$ films heat treated in $0 \%, 10 \%$ and $50 \%$ oxygen.

For the film heated in 50\% oxygen atmosphere we are unable to get intensity at the tail of the spectrum towards the Fermi energy $E_{F}$, revealing that at least the surface of this film constitutes an insulating phase or a phase with large band gap energy. This finding is reasonable because in turn we expect the films heated under low oxygen concentrations of $10 \%$ and $0 \%$ oxygen to be oxygen deficient and thus, in analogy to $\mathrm{WO}_{3}$, electronically conducting. The oxygen bonding peak at about $3 \mathrm{eV}$ is considerably sharp for the highly oxidized (50\%) film. The spectral weight of the $\mathrm{O} 2 \mathrm{p}$ bonding peak scales linear with the oxygen concentration as shown in the inset in Figure 8. We find additional confirmation for this suggestion in the W5d spectra (not shown here). The spectral intensity of the film treated in $0 \%$ oxygen appears shifted towards lower binding energies by almost $1 \mathrm{~V}$, narrowing the band gap significantly with amount of oxygen (Figure 8 right). Overall, we find increased density of states in 
the $\mathrm{VB}$ near $\mathrm{E}_{\mathrm{F}}$ with $0 \%$ and $10 \%$ oxygen concentration. Upon comparison with the VB PES spectra of $\mathrm{WO}_{3-\delta}$ [13] we notice a similar spectral behavior; this is a steep decay of intensity right from the VB maximum towards an intensity minimum, and then new spectral weight with substructures. The deconvolution of the spectra from oxygen deficient $\mathrm{WO}_{3-\delta}$ as shown in [13] shows four transitions close to the Fermi energy, which we notice also in the spectra of the $10 \%$ and $0 \% \mathrm{CuWO}_{4}$ films. Interestingly, the $0 \%$ oxygen film with the supposedly largest defect concentration is positioned in between the $50 \%$ and $10 \%$ oxygen spectrum and is thus not systematic with respect to the process parameter of oxygen concentration. This observation raises the question whether the $0 \% \mathrm{CuWO}_{4}$ film is really the one with the highest oxygen defect concentration, or not. The next question is about the band gap. For 50\% oxygen, the band gap is definitely too large for PEC because the material seems insulating when looking at the PES spectrum. The $10 \%$ oxygen treated sample has 4 or 5 gap states near $-2 \mathrm{eV}$, whereas the $0 \%$ film has 3 or 4 gap states at $-2 \mathrm{eV}$.

We would believe now that substitution of $\mathrm{WO}_{3}$ by a lower valent cation, such as $\mathrm{Mo}^{5+}$, could be an alternative to enhance the performance of $\mathrm{WO}_{3}$. This is not necessarily the case. We have substituted $\mathrm{WO}_{3}$ to $5 \%$ with various cations (including $5 \% \mathrm{Mo}$ ) and found in no single case an increased photocurrent [27]. Interestingly, if the tungsten oxide is not bulk doped, but coated with a thin Mo-oxide film on top of the $\mathrm{WO}_{3}$, then an increased photocurrent was measured [28]. According to the authors, coherent growth of the Mo oxide on the $\mathrm{WO}_{3}$ allows optimization of the electronic surface structure of the electrode while maintaining good crystallographic properties in the bulk. For the study of such complex film structures, HAXPES can be a rewarding quantitative tool. 


\section{Resonant photoemission on iron oxide films}

An oxygen deficient surface is not only characteristic for tungsten and titanium based oxides, but also for iron oxide. Hematite, $\alpha-\mathrm{Fe}_{2} \mathrm{O}_{3}$ is a promising photoanode material and should nominally contain only $\mathrm{Fe}^{3+}$. Our $\mathrm{Fe} 3 \mathrm{p}$ resonant photoemission spectra (SoLiAs end station at BESSY-II) on dip coated hematite films, heat treated at $500^{\circ} \mathrm{C}$ in air, show a clear $\mathrm{e}_{\mathrm{g}}$ structure which is indicative to $\mathrm{Fe}^{2+}$. We have anodized (electrochemically oxidized) such hematite films in 1 molar $\mathrm{KOH}$ electrolyte at potentials of $500 \mathrm{mV}$ to $700 \mathrm{mV}$ and find that the spectral weight of this $\mathrm{Fe}^{2+}$ signature decreases with increasing anodization time and potential, revealing that the oxygen deficient iron oxide surface gets more oxidized [29]. Such "anodization" in fact means that the photoanode is under PEC operational conditions. The question therefore arises whether a thermal, oxidative post-treatment is necessary for such photoanode when it is becoming oxidized anyway during oxidation. Oxidative plasma treatment of iron oxide photoanodes, for comparison, indeed causes an improvement of the photocurrent as far as the onset potential is concerned [30].
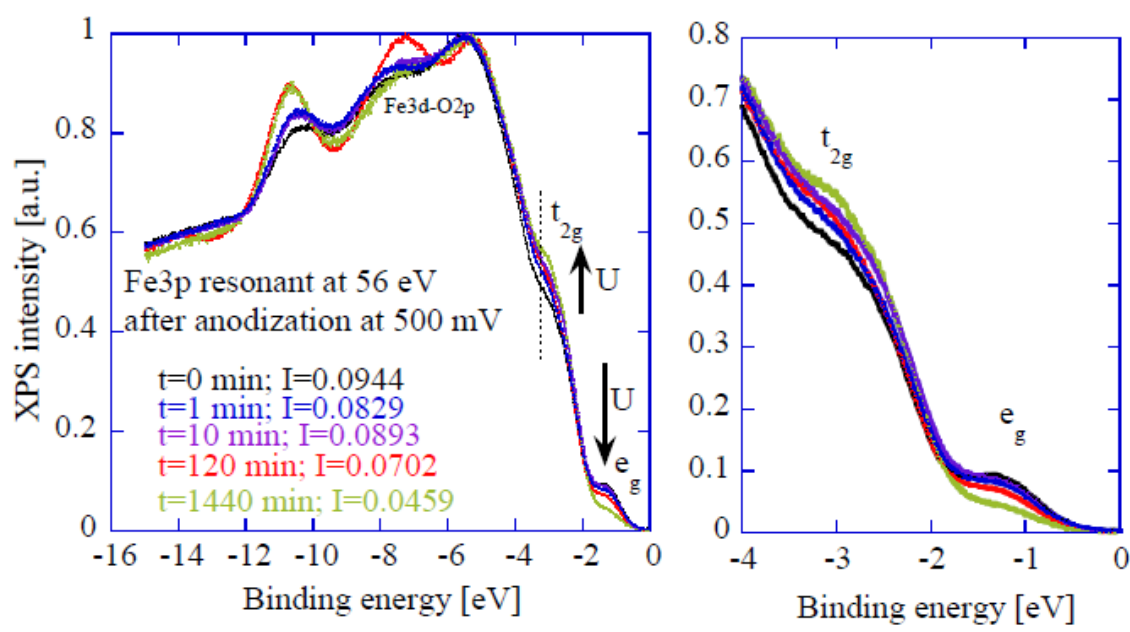

Figure 9: Fe3p resonant VB PES spectra (56 eV excitation energy) of hematite anodized at $500 \mathrm{mV}$ for up to 24 hours, showing redistribution of spectral weight for $e_{g}$ and $t_{2 g}$. 
It is hardly possible to identify the $\mathrm{e}_{\mathrm{g}}$ structure in the VB spectra unless a resonant excitation is done. The Fe2p resonant spectra (recorded at BL 7.0.1. at ALS) of similar anodized samples move towards the Fermi energy with increasing anodization potential, revealing that the anodization and transformation of $\mathrm{Fe}^{2+}$ towards $\mathrm{Fe}^{3+}$ can be interpreted as electron hole doping [31].
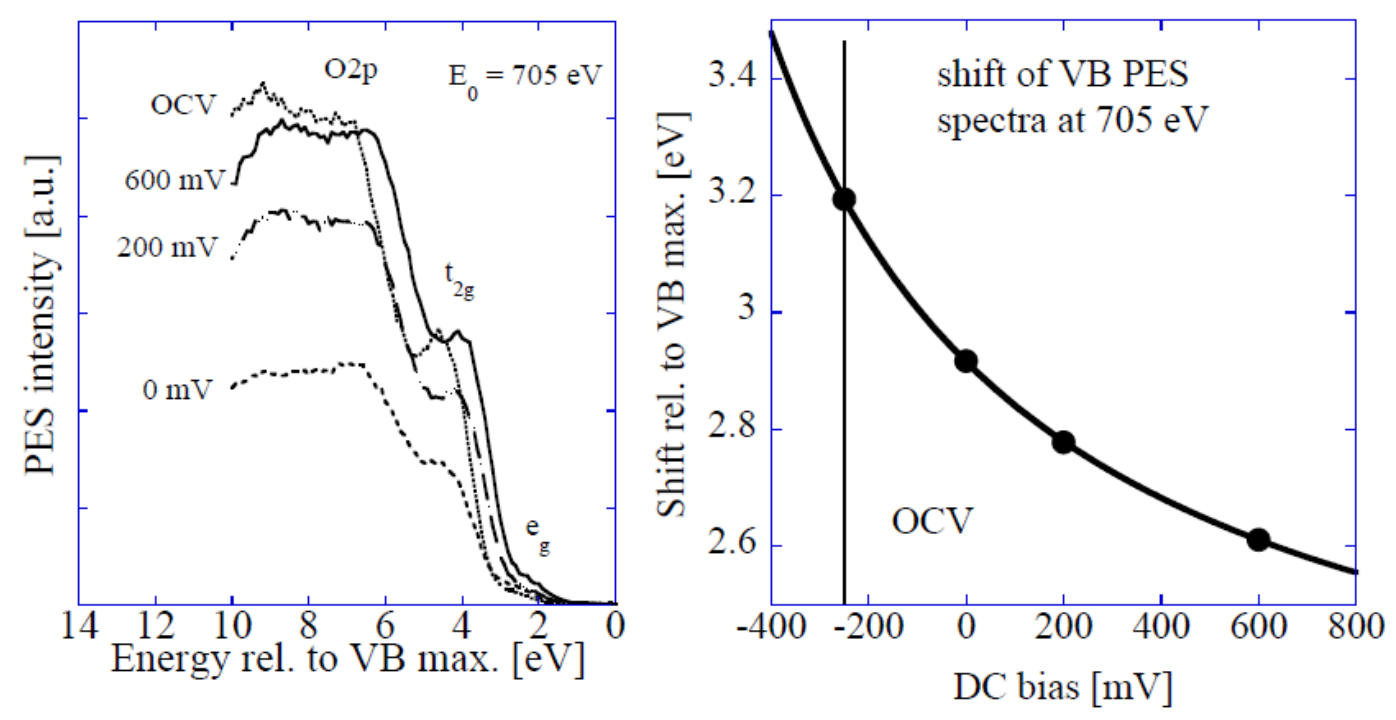

Figure 10: Left - Fe2p resonant VB PES spectra of hematite at open circuit potential (OCV), and anodized at $0 \mathrm{mV}$ to $600 \mathrm{mV}$, showing shift towards Fermi level. Right Shift of resonant VB PES spectra scales systematically with anodization potential.

Now that we have learnt what effect doping can have on metal oxides, and what anodization can do to iron oxide films, we want to check on the x-ray spectral response of the photoanodes when they are excited with visible light. A UV light induced effect has been observed recently on the UPS spectra of hematite [32]. In Figure 11 we show how we have mounted and applied a solar simulator at the SoLiAs end station at BESSY-II while we recorded Fe3p resonant XPS spectra on pristine 
J. Electron Spectroscopy and Related Phenomena:

Special Issue on The Spectroscopy of Energy Materials, submission deadline 31. August 2012

hematite with excitation energies from $46-62 \mathrm{eV}$. Exposure to simulated solar light causes an overall decrease of the VB XPS spectrum, but we measure a particular response at $57.5 \mathrm{eV}$ excitation.
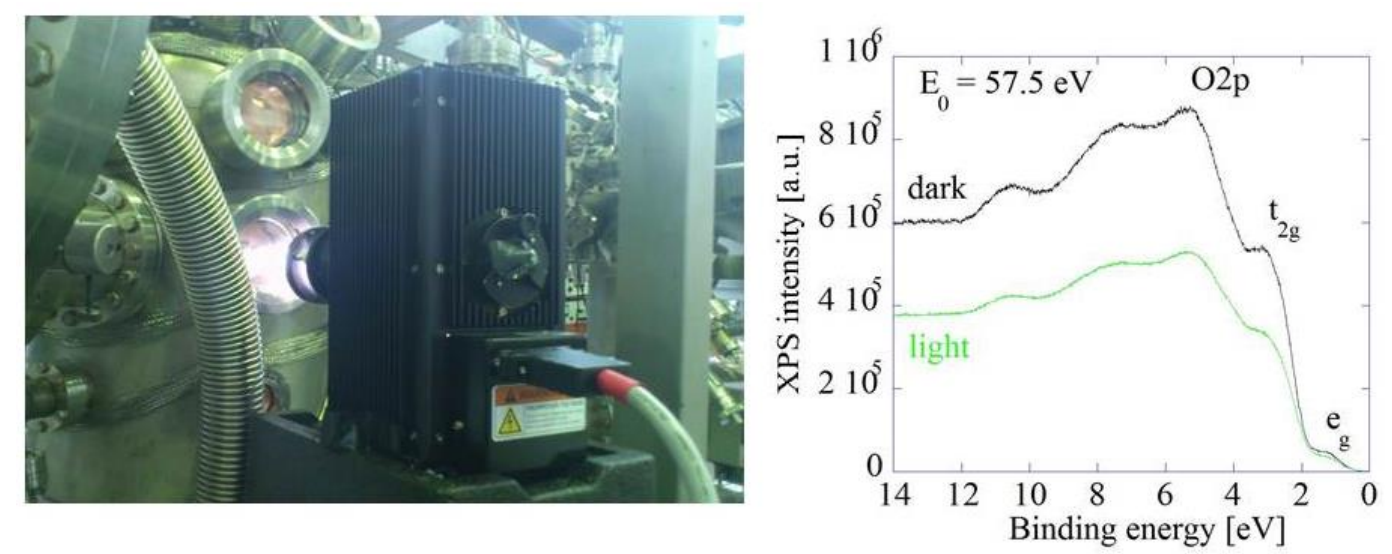

Figure 11: Solar simulator shining onto hematite sample in UHV chamber during XPS at SoLiAs, BESSY-II. Fe3p resonant XPS spectra on pristine hematite thin film in dark (top spectrum) and under solar simulator illumination (bottom spectrum).

An overview of all VB spectra (not shown here) shows significant differences between the spectra recorded under the dark/light experimental conditions, mainly for the resonant excitation range $\mathrm{E}_{0}=56-58 \mathrm{eV}$. The intensity changes of the $\mathrm{O} 2 \mathrm{p}$ bonding peak and $t_{2 g}$ and $e_{g}$, orbital symmetry transitions are shown on Figure 12 . The "light" effect for $\mathrm{E}_{0}=57.5 \mathrm{eV}$ is actually well demonstrated in the "dark" measurement by the absence of a resonant enhancement at $\mathrm{E}_{0}=57.5 \mathrm{eV}$. Generally, it looks like the excitation with visible light suppresses the resonant effect observed under "dark" conditions, due to the equal excitation of all states. 

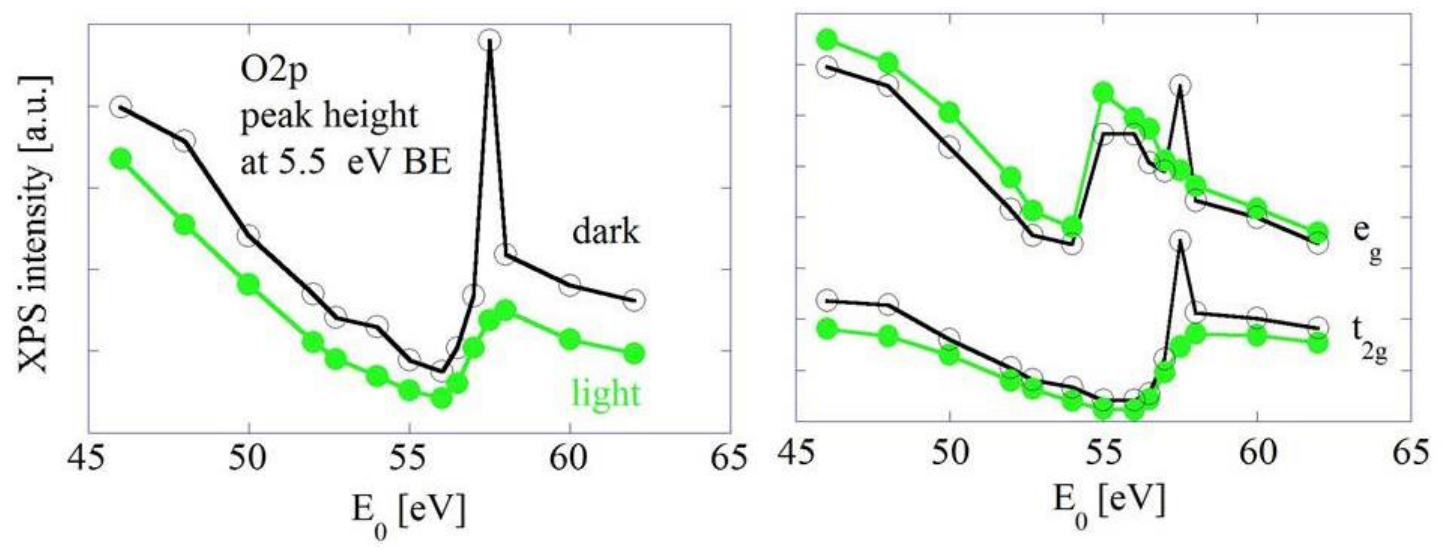

Figure 12: Intensities of the characteristic $\mathrm{O} 2 \mathrm{p}$ (left), $\mathrm{t}_{2 \mathrm{~g}}$ and $\mathrm{e}_{\mathrm{g}}$ (right) transition maxima in dark (open symbols) and under illumination (filled symbols).

The position of the $\mathrm{O} 2 \mathrm{p}$ peak shifts significantly between $56-60 \mathrm{eV}$, and the $\mathrm{t}_{2 \mathrm{~g}}$ transition between $56-58 \mathrm{eV}$, but only in the latter case no significant difference can be seen between the "dark" and illuminated measurements, in spite of the significant difference in the peak intensities for $\mathrm{E}_{0}=57.5 \mathrm{eV}$. When we normalize the spectra of the "dark" and illuminated samples to the O2p bonding peak, a slight shift $(0.15-0.2$ $\mathrm{eV}$ ) of the latter spectrum towards the Fermi energy is noticeable, suggesting enhanced conductivity of the sample due to the excitation with visible light. We hope that some cross fertilization from condensed matter physics towards PEC and APS can take place soon in as far as a UV light induced effect of two dimensional electron gas formation on $\mathrm{SrTiO}_{3}$ [33] and on $\mathrm{KTaO}_{3}$ [34] was discovered recently.

\section{Probing solid-liquid interface and photo-electrochemical systems operando}

Recent progress in instrumentation and sample environment allows to record soft $\mathrm{X}$ ray NEXAFS spectra from samples in liquid environment. This includes the liquid jet systems [35] and the systems that use liquid cells with silicon nitride windows [36]. Latter are very well suited for photo-electrochemical operando experiments, which 
we recently demonstrated on a hematite photoanode [37]. The nominally $30 \mathrm{~nm}$ thin, $1 \%$ Si doped hematite film was deposited with ambient pressure CVD on a $100 \mathrm{~nm}$ thin $\mathrm{Si}_{3} \mathrm{~N}_{4}$ window [Silson, UK], with a $10 \mathrm{~nm} \mathrm{Au}$ and $1 \mathrm{~nm} \mathrm{Cr}$ metal current collector layer in between them. The frame side is exposed to UHV and allows entrance of Xrays from the beamline for photon in - photon-out spectroscopy, as well as exposure to visible light from a solar simulator in order to optically excite the system and producing a photocurrent. The film is exposed from the back side to $0.1 \mathrm{molar} \mathrm{KOH}$ electrolyte and electrically wired in an electrochemical 3-electrode configuration.

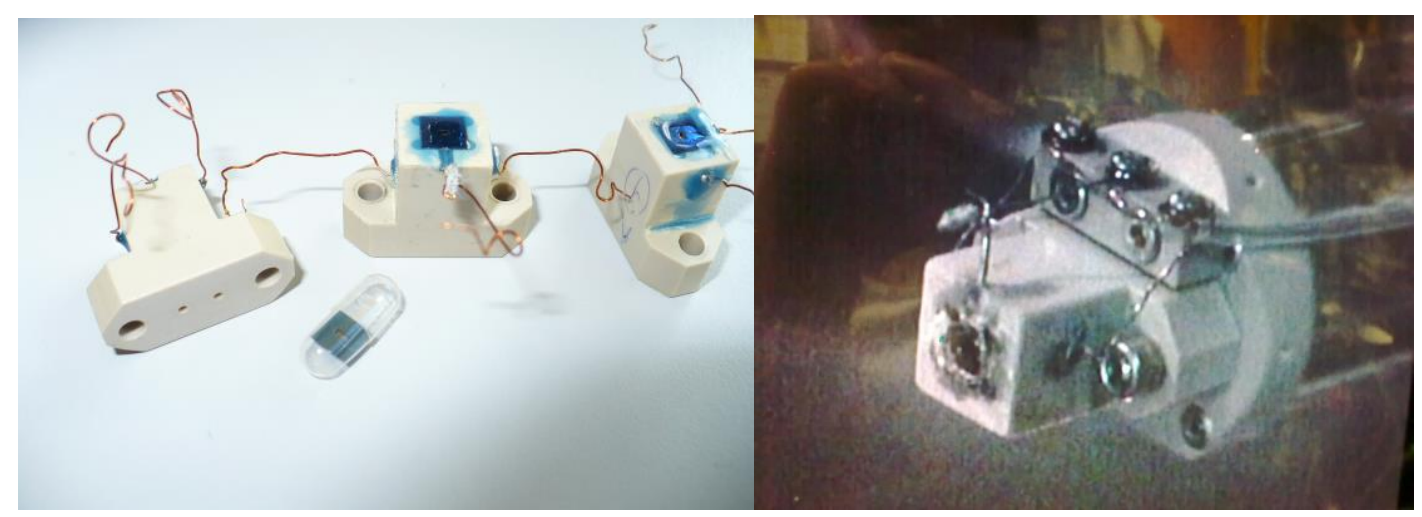

Figure 13: Left - Photoelectrochemical cells with $\mathrm{Si}_{3} \mathrm{~N}_{4}$ frames with hematite films and 3-electrode terminals. Right - Cell mounted and contacted on sample holder in UHV chamber during data acquisition for in-situ soft x-ray experiments at ALS BL7.

Depending on the applied bias potential, two new states evolved in the pre-edge of the oxygen NEXAFS spectra (Figure 14, left), but only when the solar simulator light was pointed on the sample. These new states were tentatively assigned to electron hole states into the charge transfer band (CTB) and upper Hubbard band (UHB) [37]. The spectral weight of both states scales with the applied bias potential and follows two different trends (Figure 14, top right). The state into the CT band follows a square root type behavior and suggests that it may originate from the depletion layer, the 
width of which is known to scale with the bias potential. The state into the UHB can be modeled with a Gaussian, the maximum of which is at the same bias potential where the photocurrent sets on.
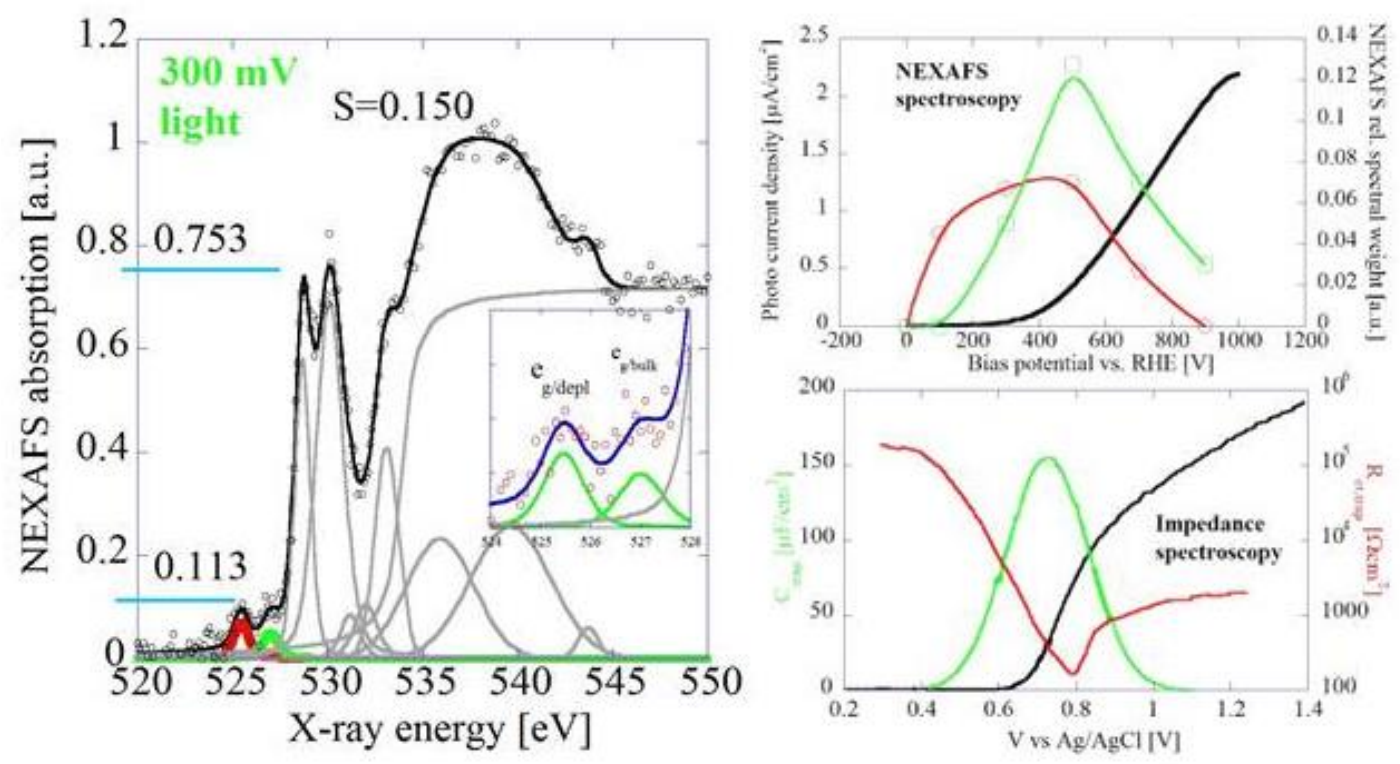

Figure 14: Left - Oxygen NEXAFS spectrum recorded in-situ with $300 \mathrm{mV}$ bias potential and while under exposure to 1.5 AM solar simulated light. The inset shows the two hole peaks at $525 \mathrm{eV}-527 \mathrm{eV}$ magnified. Right - Comparison of photocurrent and spectral weight of the two NEXAFS hole peaks [37] with surface states obtained from electrochemical impedance spectroscopy [38].

This interesting observation matches the outcome of an even more recently published study with electrochemical impedance spectroscopy (EIS), where a suspected surface state derived from EIS [38] has the same dependence from the bias potential (Figure 14, bottom right). During the compilation of this manuscript in late August 2012, we learnt about a new manuscript [39] which shows that EIS can detect even three new states on hematite. We can confirm this suggestion in as far as in our recent campaign at BL 7.0.1 in April 2012 we identified three pre-edge peaks in the hematite oxygen depending on the applied bias potential. Interestingly, we found this on the sample in 
"dry" condition when the hematite was not in contact with electrolyte and the potential was applied in lateral configuration.

\section{Influence of processing on the microstructure}

Not only doping, but also microstructural changes can have changes on the photocurrent of photoelectrodes. The study shown in [27] was actually targeted at altering the microstructure of tungsten oxide by $3^{\text {rd }}$ element doping such as Si or Mo. Also in the case of $\mathrm{Si}$ doped hematite, $\mathrm{Si}$ is believed to act as a structure directing agent [40], rather than a constituent with a direct influence on the electronic structure. Figure 15 (left) shows the colorated scanning electron micrograph of a region of hydrothermally after-treated hematite film. The original turf like sample surface (not shown here) has turned into one with stellate structures and also a significantly higher photo current [41]. The microstructures of such films depend on the $\mathrm{pH}$ of the hydrothermal solution and affect slightly the $\mathrm{O}$ and Fe NEXAFS spectra. In Figure 15 (right) we show a resonant inelastic x-ray scattering (RIXS) O1s spectral map of such sample hydrothermal processed at $\mathrm{pH}=2.36$.
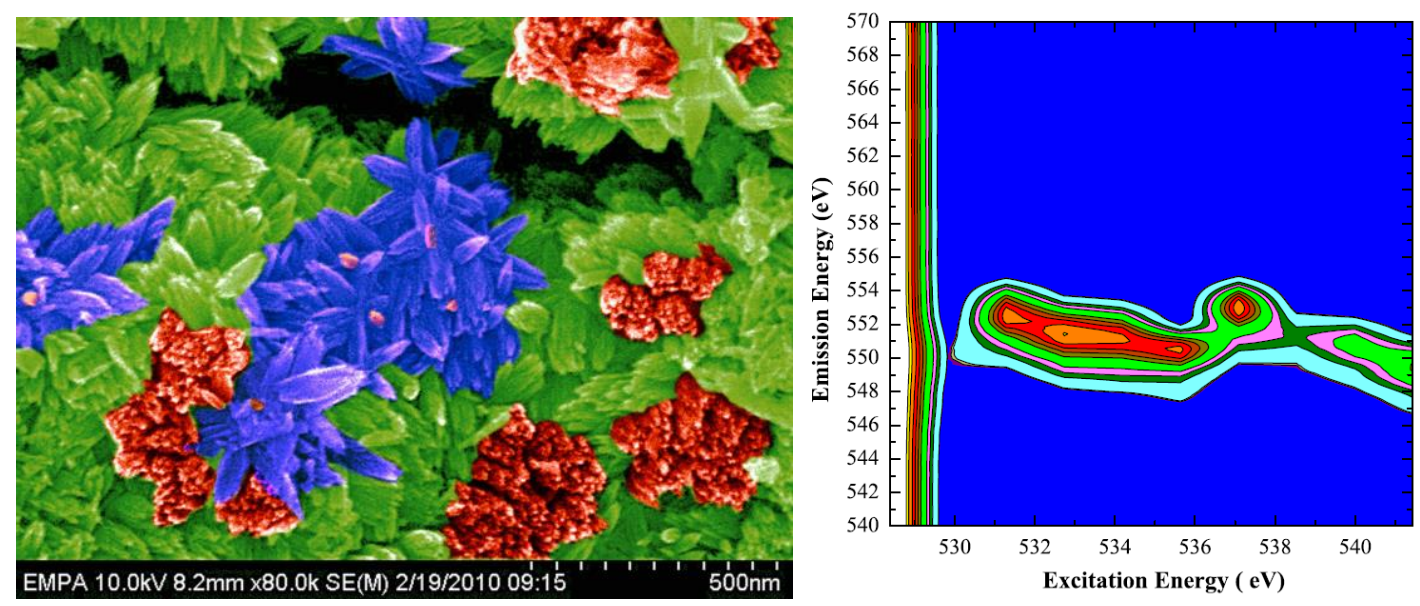

Figure 15: Left - Hematite re-structured by hydrothermal after. Right - O1s RIXS map of the sample treated hydrothermal in $\mathrm{pH}=2.36$. 


\section{Protein spectroscopy}

So far, we have presented spectroscopy methods on inorganic matter, whereas photosynthesis in plants is based on animate matter. The title of this Special Issue on "Energy Materials" would at least literally not include "Molecular Systems", although latter have close connection with natural and artificial photosynthesis. Functionalization of hematite surfaces with phycocyanin, a light harvesting protein in blue green algae, makes an increased photocurrent [42], see Figure 16 (left). It is therefore logical to expand our studies to such biological or bio-inspired systems. And protein x-ray spectroscopy has been done for many decades. In the former, proteins play a substantial role for the solar energy conversion by water splitting and subsequent formation of hydrocarbons.
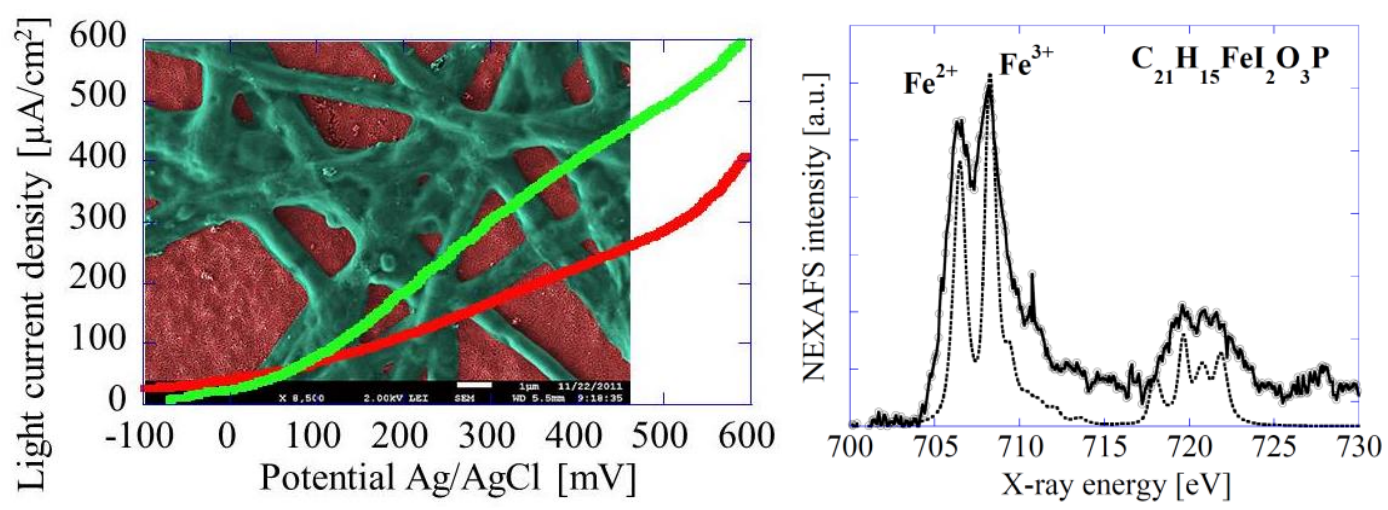

Figure 16: Left - Scanning electron micrograph (courtesy Dr. E Vitol, Argonne National Laboratory) of hematite functionalized with phycocyanin, with overlaid light current densities of pristine hematite (lower red line) and functionalized hematite (upper green line). Right - Multiplett simulation and experimental Fe2p NEXAFS spectra of a synthetic hydrogenase model (synthesized by Prof. Xile Hu, EPFL).

Some algae and bacteria, using sunlight as their energy source, release hydrogen under certain conditions. Their hydrogenases (H2ases) catalyze production and consumption of molecular hydrogen in nature $[43,44]$. Nature shows three major 
J. Electron Spectroscopy and Related Phenomena:

Special Issue on The Spectroscopy of Energy Materials, submission deadline 31. August 2012

types of H2ases: NiFe H2ase, FeFe H2ase, and a single Fe Hmd H2ase. Different H2ases have different active sites, in which the catalysis takes place.

H2ases are of particular interest because of their hydrogen evolving center. But their spectroscopic assessment has been troubled by the fact that most of them are iron based, i.e. 2 iron atoms bridged by 2 sulfur atoms (alternatively $1 \mathrm{Fe}$ and $1 \mathrm{Ni}$ ), and they have a large Fe-S co-factor with several dozen atoms, the Fe part of which overshadow the Fe signal from the hydrogen evolving center. Because of this, iron element specific X-ray spectroscopy studies were practically impossible. Hence, chemists synthesize structural H2ase models without co-factor which allow for such characterization as with EXAFS or L-edge spectroscopy.

Figure 16 (right) shows the Fe L-edge multiplett of such model, together with the atomic multiplett simulation [45]. We notice particular differences of the $t_{2 g}$ orbital symmetry peak at around $705 \mathrm{eV}$, depending on the synthesis specification. The electronic structure calculation of the H2ase model is based on Ligand Field Atomic Multiplet theory $[46,47]$. The allowed electronic transitions are $2 p^{6} 3 d^{6} \rightarrow 2 p^{5} 3 d^{7}$, and $2 p^{6} 3 d^{5} \rightarrow 2 p^{5} 3 d^{6}$ for $\mathrm{Fe}^{2+}$ and $\mathrm{Fe}^{3+}$, respectively. It is obvious that the Fe $2 p$ core hole split into $\mathrm{L}_{3}\left(2 p_{3 / 2}\right)$ and $\mathrm{L}_{2}\left(2 p_{1 / 2}\right)$ edges because of the spin orbit coupling, and each edge is additionally split by multiplet effects and crystal field splitting. Besides, in octahedral $\left(\mathrm{O}_{\mathrm{h}}\right)$ symmetry the $3 d$ orbitals are split into $\mathrm{e}_{\mathrm{g}}\left(\mathrm{d}_{\mathrm{x}-\mathrm{y}}^{2}{ }^{2}, \mathrm{~d}_{\mathrm{z}}{ }^{2}\right)$ and $\mathrm{t}_{2 \mathrm{~g}}\left(d_{x y}, d_{y z}\right.$, $d_{x z}$ ) orbitals with an energy difference of $10 \mathrm{Dq}$. The calculations for $\mathrm{Fe}^{2+}$ and $\mathrm{Fe}^{3+}$ assume $\mathrm{O}_{\mathrm{h}}$ symmetry. The ligand field parameters were adjusted and Slater integrals of atomic values scaled down in order to reproduce covalency effects therefore to yield a good agreement between the experimental and calculated spectra. The best fit was obtained by using $10 \mathrm{Dq}=1.80 \mathrm{eV}$ for $\mathrm{Fe}^{2+}$ and $10 \mathrm{Dq}=1.70 \mathrm{eV}$ for $\mathrm{Fe}^{3+}$. From the 
J. Electron Spectroscopy and Related Phenomena:

Special Issue on The Spectroscopy of Energy Materials, submission deadline 31. August 2012

comparison of experimental and calculated spectra shown in Fig. 16, we find that our hydrogenase model has approximately $35 \%$ of $\mathrm{Fe}^{2+}$, and $65 \%$ of $\mathrm{Fe}^{3+}$ both in high spin state with total spin $S=2$ and $S=5 / 2$, respectively. We conclude that the first peak in Fig. 16 (right) is due to $\mathrm{Fe}^{2+}$ along with an overlap with $\mathrm{e}_{\mathrm{g}}$ states of $\mathrm{Fe}^{3+}$ and the second peak is mainly because of $\mathrm{t}_{2 \mathrm{~g}}$ states of $\mathrm{Fe}^{3+}$.

\section{- Nuclear resonant vibrational spectroscopy for iron-specific studies}

Nuclear resonant vibrational spectroscopy (NRVS) is a relatively new X-ray based method for vibration spectroscopy. It scans an extremely monochromatic $(\sim 1 \mathrm{meV})$ X-ray beam through the ${ }^{57} \mathrm{Fe}$ nuclear resonance at $14.4 \mathrm{KeV}$, and measures the corresponding creation (Stokes) or annihilation (anti-Stokes) of phonons $[48,49]$ (Figure 17 a). NRVS is a proven pin-point tool to study iron-specific chemistry and biochemistry [48,49] for complicated molecules, such as H2ases [50]. There is a number of compelling advantages of NRVS over established methods: it is water transparent in comparison with far IR spectroscopy and thus well suited for protein relevant in-situ studies in their natural aqueous environment; NRVS is free of fluorescence problems in comparison with resonance Raman spectroscopy; it distinguishes $\mathrm{O}$ vs. $\mathrm{N}$ vs. $\mathrm{C}$ in comparison with EXAFS; it is capable of selectively labeling the targeted iron sites.

The raw NRVS spectra are obtained as the delayed nuclear event signal vs. the phonon energy (excitation energy - 14.4KeV) (Figure 17, b), and then converted into the density of state (DOS) (b'). The DOS is a pure molecular property and can be simulated via normal mode analysis (NMA) to obtain vibrational force constants, molecular structures, as well as reaction mechanisms. 
Similar to far-IR spectroscopy, Fe-S and Fe-P bands appear in the low frequency region (150-400 $\left.\mathrm{cm}^{-1}\right), \mathrm{Fe}-\mathrm{CN},-\mathrm{CO}$ and $-\mathrm{NO}$ appear in the middle region of 400-650 $\mathrm{cm}^{-1}$ (Figure 17, $\mathrm{b}^{\prime}$ and c), whereas $\mathrm{X}-\mathrm{Fe}-\mathrm{H}$ or $\mathrm{Fe}-\mathrm{H}-\mathrm{X}$ bending is at around $800 \mathrm{~cm}^{-1}$ (Figure 17, d). Certainly, NMA and DFT calculations will add value to understanding of these spectra. Even without simulations, these frequencies may be identified.
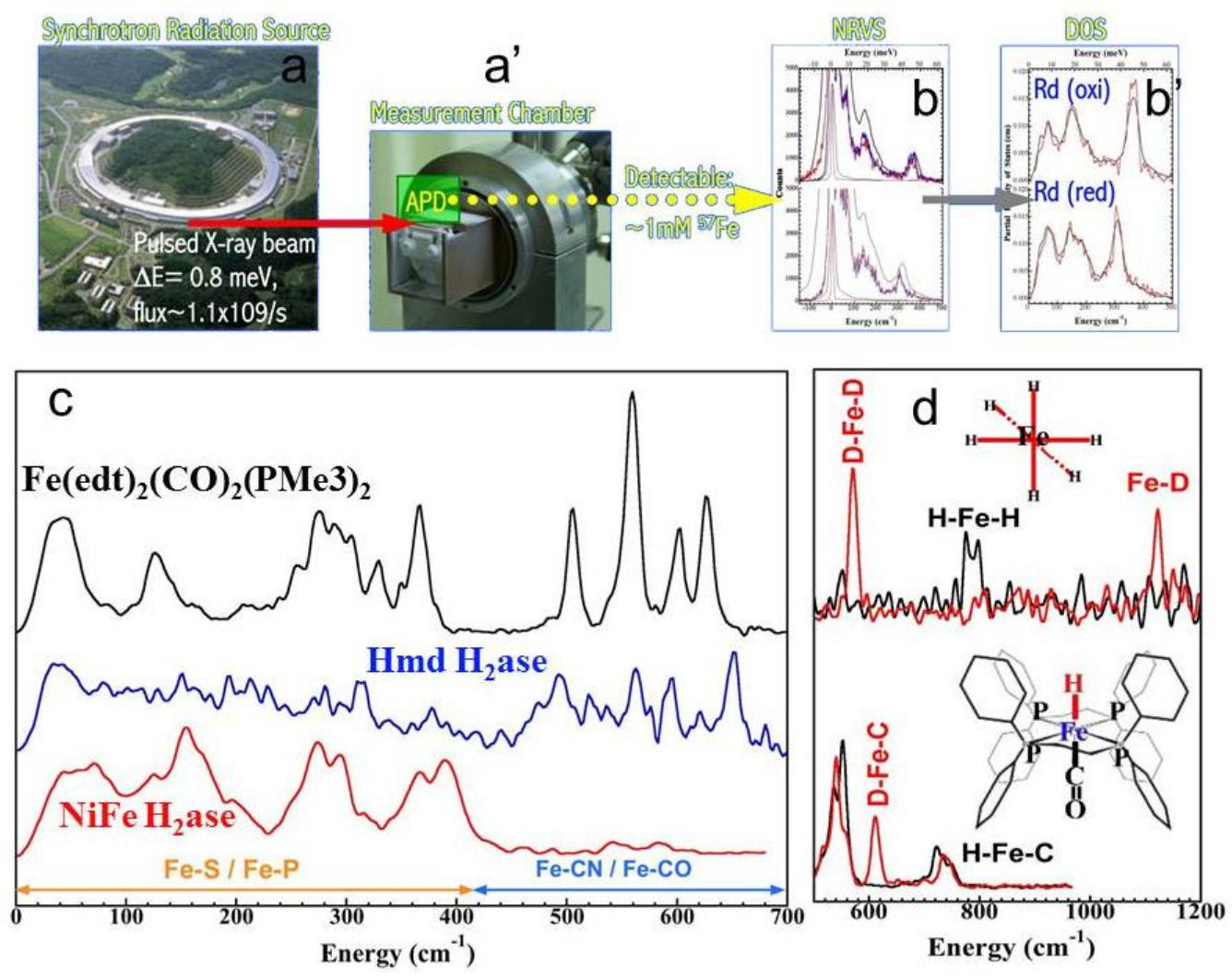

Figure 17: (a, a') Synchrotron radiation source and experimental setup for NRVS; (b, b') NRVS and DOS of rubredoxin (Rd); (c) DOS of (from top down) $\mathrm{Fe}(\mathrm{edt}) 2(\mathrm{CO}) 2(\mathrm{PMe} 3) 2$ complex, Hmd H2ase and NiFe H2ase; d) NRVS of (from top down) $\mathrm{Fe}(\mathrm{H} / \mathrm{D}) 6$ and. $\mathrm{Fe}(\mathrm{D}) \mathrm{CO}$.

For studying real H2ases, we start with the Hmd [49] which has only one Fe inside each enzyme molecule and has no Fe-S clusters. The Hmd NRVS spectrum has virtually no absorption in the $\mathrm{Fe}-\mathrm{S}$ region but a prominent features in the $\mathrm{Fe}-\mathrm{CO}$ region, which is similar with the model complex of $\mathrm{Fe}(\mathrm{edt}) 2(\mathrm{CO}) 2(\mathrm{PMe} 3) 2 . \mathrm{NiFe}$ 
H2ase has Fe-S features (Figure 17, b' vs. c) as its main NRVS feature, due to the 11 $\mathrm{Fe}$ in the $\mathrm{Fe}-\mathrm{S}$ clusters [51]. Under this situation, the weak $\mathrm{Fe}-\mathrm{CN} / \mathrm{Fe}-\mathrm{CO}$ features are harder to resolve.

Measuring Fe-H vibrations in H2ases are highly desired but not reported yet. The first NRVS on Fe-H/D models was reported by Cramer and coworkers [52] on [FeH6] and [FeD6]. The $\mathrm{H}-\mathrm{Fe}-\mathrm{H} / \mathrm{D}-\mathrm{Fe}-\mathrm{D}$ bend modes and even the Fe-D stretching mode $\left(1122 \mathrm{~cm}^{-1}\right)$ are observed. The Fe-H stretching at $\sim 1900 \mathrm{~cm}^{-1}$ is practically out of the range of NRVS detection [52]. The Fe-H/D complexes, which has only one $\mathrm{H}$ attached to the iron and is closer to the real H2ases' catalytic centers, is presented as in Figure 17 (d). Its X-Fe-H $\left(730-750 \mathrm{~cm}^{-1}\right)$ and X-Fe-D $\left(600-610 \mathrm{~cm}^{-1}\right)$ features are also significant. Here $\mathrm{X}=\mathrm{C}$ in the diatomic $\mathrm{CO}$ ligand in the trans- position [53].

Although NRVS detection on $\mathrm{Fe}-\mathrm{H}$ for real H2ases could be complicated by the diluteness and the complexity of the enzymes, the evidence presented here clearly demonstrates the feasibility to probe X-Fe-H/D bending modes in the region of 580$800 \mathrm{~cm}^{-1}$. As the synchrotron radiation beamtimes and detectors progress, we believe, the detection in bridging hydride vibrations, such as the $\mathrm{Ni}-\mathrm{H}-\mathrm{Fe}$ in $\mathrm{Ni}-\mathrm{R}(\mathrm{NiFe}$ $\mathrm{H} 2 \mathrm{ase}$ ), will become feasible in the future.

\section{Summary and Outlook}

We have investigated metal oxide photoanode surfaces and sub-surfaces with conventional XPS and resonant photoemission spectroscopy in vacuum and in high oxygen or water vapor pressure. Oxygen deficiency on the surface and bulk which constitute electronic defects can be monitored and related with the transport properties and water splitting performance and traced back to synthesis and processing conditions of materials and components for water splitting. So-called ambient 
J. Electron Spectroscopy and Related Phenomena:

Special Issue on The Spectroscopy of Energy Materials, submission deadline 31. August 2012

pressure XPS is quite suitable for the understanding and monitoring of the materials engineering processes such as heating, oxidation and reduction. The availability of HAXPES is particularly suited for the quantitative assessment of multilayered photoelectrodes and heterostructures. The possibility to use liquid cells in UHV chambers to obtain for example spectra from water and alcohol mixtures [54] and similar mixtures [55] may find in future more use when not only water splitting (photolysis) experiments are made, but when actually photosynthesis is performed in liquid cells and (liquid) hydrocarbons are formed in the cell which can be accumulated and detected and the underlying processes studied. This should in general be feasible now. The liquid cell was here used to perform an actual photoelectrochemical study on a photoanode under realistic water splitting operation conditions, and the changes in the valence band upon bias and illumination can be well compared with impedance spectroscopy. Meanwhile, conventional methods like NEXAFS and standard XPS are still useful under ex-situ conditions. The complexity of assemblies and device components from the materials perspective can be well addressed with the readily available tools, and complex molecules like proteins in general and, say, hydrogenases in particular will bear less and less secrets with promising methods such as nuclear resonant vibrational spectroscopy. Overall, it is very encouraging to see the overwhelming progress of synchrotron based spectroscopy methods including the very complex sample environment. Both will find their match in the very complex field of materials, molecules and devices for artificial photosynthesis (AP). We have not addressed time resolved studies and the capabilities of the free electron lasers in this paper. Both will also have tremendous impact on the development of AP science technology in the following years. Scientists and engineers active in both fields will have the privilege of facing an exciting new era. 
J. Electron Spectroscopy and Related Phenomena:

Special Issue on The Spectroscopy of Energy Materials, submission deadline 31. August 2012

\section{Acknowledgment}

The research leading to these results received funding from the Swiss Federal Office of Energy contracts 152316-101883, 153613-102809, and 153476-102691, European Community's Seventh Framework Program Novel Materials for Energy Applications grant no. 227179 (Nanostructured Photoelectrodes for Energy Conversion); the Swiss NSF grants R'Equip \#206021-121306 (Fundamental Aspects of Photocatalysis and Photo-electrochemistry/Basic Research Instrumentation for Functional Characterization), \#200021-132126 (Defects in the bulk and on surfaces and interfaces of metal oxides with photo-electrochemical properties: In-situ photoelectrochemical and resonant x-ray and electron spectroscopy studies), \#IKZ-133944 (Oxide heterointerfaces in assemblies for photo-electrochemical applications), \#200021-137868 (Reaction-diffusion processes for the growth of patterned structures and architectures: A bottom-up approach for photo-electrochemical electrodes). R.T. is funded by the SNF Marie Heim-Vögtlin Fellowship \#139698 (Self-organization processes to pattern thin films: A bottom-up approach for photoelectrodes). K. G.-S. is supported by Sciex project \#10.013 (Nanobio-Interfaces for Photocatalytic Solar Hydrogen) and by the VELUX Foundation (Biomimetic photo-electrochemical cells for solar hydrogen generation).

The ALS is supported by the Director, Office of Science, Office of Basic Energy Sciences, of the U.S. Department of Energy under Contract No. DE-AC0205CH11231. The HAXPES instrument at PETRA III is jointly operated by the University of Würzburg (R. Claessen), the University of Mainz (C. Felser) and DESY. Funding by the Federal Ministry of Education and Research (BMBF) under contracts 05KS7UM1, 05K10UMA, 05KS7WW3, and 05K10WW1 is gratefully acknowledged. S.M. and D.D.S. acknowledge Mission on Nano Science and 
Technology (Nano Mission) program, Government of India, for the access to PETRA III facilities. Collaboration of A.B. and D.D.S is based on Indo-Swiss project ISJRP \#138 864 (Electronic origin of Cr poisoning in ceramic fuel cell cathodes). NRVS was performed at APS and SPring-8 under leadership of Dr. S. P. Cramer of UC Davis and LBN, supported by NIH (GM-65440) and US Department of Energy - both to Dr. Cramer. A.B is particularly indebted to Prof. Dr. Andreas Luzzi and Prof. Thomas Graule for supporting his PEC research and Dr. Elena Rozhkova (ANL) and Prof. Xile $\mathrm{Hu}$ (EPFL) for support of the protein based research. Reflectometry was performed by Dr. Tzu-Wen Huang, Empa.

\section{References}

[12] Matsuno, J.; Mizokawa, T.; Fujimori, A.; Mamiya, K.; Takeda, Y.; Kawasaki, S.; Takano, M. Phys. Rev. B 1999, 60(7), 4605.

[1] Braun, A.; Augustynski, J.; Chandler, E.A.; Mao, S.S.; Miller, E.L.; Turner J.A.; Ye J.H., J. Mater. Res. 2010, 25 (1), 1-2.

[2] Photoelectrochemical Hydrogen Production, Series: Electronic Materials: Science \& Technology, Vol. 102, van de Krol, Roel; Grätzel, Michael (Eds.) 2012, 2012, VIII, 321 p. 124 illus.

[3] Feng Jiao, Heinz Frei, Chem. Comm. 2010, 46(17), 2920-2922.

[4] Johannes Messinger, John H. Robblee, Uwe Bergmann, Carmen Fernandez, Pieter Glatzel, Hendrik Visser, Roehl M. Cinco, Karen L. McFarlane, Emanuele Bellacchio, Shelly A. Pizarro, Stephen P. Cramer, Kenneth Sauer, Melvin P. Klein, Vittal K. Yachandra,

J. Amer. Chem. Soc. 2001, 123(32), 7804-7820.

[5] Asahi R, Morikawa T, Ohwaki T, Aoki K, Taga Y., Science 2001 (293), (5528):269-71.

[6] A. Braun, K.K. Akurati, G. Fortunato, F.A. Reifler, A. Ritter, A.S. Harvey, A. Vital, T. Graule, J. Phys. Chem. C, 2010, 114 (1), 516-519.

[7] Jean-Marie Herrmann, New J. Chem., 2012, 36, 883-890 
[8] A. Fujishima, K. Honda, Nature 238, pp. 37-38, 1972.

[9] Impedance Spectroscopy: Theory, Experiment, and Applications, 2nd Edition, Evgenij Barsoukov (Editor), J. Ross Macdonald (Editor), Wiley Publishers, ISBN: 978-0-471-64749-2.

[10] Frank E. Osterloh, Chem. Mater. 2008, 20, 35-54.

[11] Michael Grätzel, Nature 414, 338-344 (15 November 2001).

[12] J. Augustyński, R. Solarska, H. Hagemann, C. Santato, Proc. of SPIE (The International Society for Optical Engineering) vol. 6340, 63400J-1 (2006)].

[13] A. Braun, S. Erat, X. Zhang, Q. Chen, F. Aksoy, R. Löhnert, Z. Liu, S.S. Mao, T. Graule, J. Phys. Chem. C, 2011, 115 (33), 16411-16417 http://pubs.acs.org/doi/abs/10.1021/jp202375h

[14] Bringans, R. D.; Höchst, H.; Shanks, H. R. Phys. Rev. B 1981, 24, 3481-3489.

[15] Bullett, D.W. J.; Phys., C Solid State Phys. 1983, 16, 2197-2207.

[16] Lusvardi V.S.; Barteau M.A.; Chen J.G.; Eng J.J.; Teplyakov A.; Fruhberger B., Surface Science 1998, 397(1) 237-250.

[17] A Braun, F. Aksoy Akgul, Q. Chen, S. Erat, T.-W. Huang, N. Jabeen, Z. Liu, B. S. Mun, S. S. Mao, X. Zhang, Chem. Mater., in press, http://pubs.acs.org/doi/abs/10.1021/cm301829y

[18] Nanda, J. et al, J. Appl. Phys. 90, 2504 (2001)

[19] Nanda, J. et al, Phys. Rev. B. 59, 7473 (1999)

[20] Sapra S. et al., J. Phys. Chem. B 110, 15244 (2006).

[21] P K Santra et al, J. Am. Chem. Soc. 131, 470 (2009)

[22] R. Claessen et al. New Journal of Physics 11, 125007 (2009)

[23] D D Sarma et al, J. Phys. Chem. Lett. 1, 2149 (2010)

[24] S Granoth et al, J. Electron. Spectrosc. 183, 80 (2011)

[25] Andrei Gloskovskii, Gregory Stryganyuk, Gerhard H. Fecher, Claudia Felser, Sebastian Thiess, Heiko Schulz-Ritter, Wolfgang Drube, Götz Berner, Michael Sing, Ralph Claessen, Masafumi Yamamoto, J of Electron Spectroscopy and Related Phenomena 2012, 185( 1-2), 47-52.

[26] Y. Chang, A. Braun, A. Deangelis, J. Kaneshiro, N. Gaillard, J. Phys. Chem. C, 2011, 115 (51), pp 25490-25495 http://pubs.acs.org/doi/citedby/10.1021/jp207341v 
[27] R. Solarska, B.D. Alexander, A. Braun, R. Jurczakowski, G. Fortunato, M. Stiefel, T. Graulea, J. Augustynski, Electrochimica Acta 55 (2010) 7780-7787.

[28] Nicolas Gaillard, Brian Cole, Jess Kaneshiro, Eric L. Miller, Bjorn Marsen, Lothar Weinhardt, Marcus Bär, Clemens Heske, Kwang-Soon Ahn, Yanfa Yan and Mowafak M. Al-Jassima, J. Mater. Res. 2010, 25(01) 45-51.

[29] K. Gajda-Schrantz, S. Tymen, F. Boudoire, R. Toth, D. K. Bora, W. Calvet, M. Grätzel, E. C. Constable, A. Braun, submitted to PCCP Special Issue Electrified Interface Chemistry

[30] I. Herrmann-Geppert, P. Bogdanoff and S. Fiechter, Check also: ECS Trans. 2012, Volume 41, Issue 33, Pages 201-212.

[31] A. Braun, Q. Chen, D. Flak, G. Fortunato, K. Gajda-Schrantz, M. Grätzel, T. Graule, J. Guo, T.-W. Huang, Z. Liu, A. Popelo, K. Sivula, H. Wadati, P. P. Wyss, L. Zhang, J. Zhu; ChemPhysChem Special Issue: Electrochemisty and Energy, Volume 13, Issue 12, pages 2937-2944, August 27, 2012

[32] D.S. Toledano, E.R. Dufresne, V.E. Henrich, J. Vac. Sci. Technol. A 1998, 16(3) 1050-1054. http://dx.doi.org/10.1116/1.581231

[33] W. Meevasana, P. D. C. King, R. H. He, S-K. Mo, M. Hashimoto, A. Tamai, P. Songsiriritthigul, F. Baumberger, Z-X. Shen, Nature Materials 10,114-118 (2011) doi:10.1038/nmat2942

[34] P. D. C. King, R. H. He, T. Eknapakul, P. Buaphet, S.-K. Mo, Y. Kaneko, S. Harashima, Y. Hikita, M. S. Bahramy, C. Bell, Z. Hussain, Y. Tokura, Z.-X. Shen, H. Y. Hwang, F. Baumberger, and W. Meevasana, Phys. Rev. Lett. 108, 117602 (2012)

[35] M. Faubel, K. R. Siefermann, Y. Liu, B. Abel, Acc. Chem. Res., 2012, 45 (1), $120-130$

[36] J.-H. Gua, A. Augustsson, S. Kashtanov, D. Spangberg, J. Nordgren, K. Hermansson, Y. Luo, A. Augustsson, Journal of Electron Spectroscopy and Related Phenomena 144-147 (2005) 287-290.

[37] A. Braun, K. Sivula, D. K. Bora, J. Zhu, L. Zhang, M. Grätzel, J. Guo, E. C. Constable, J. Phys. Chem. C 2012, 116 (32), 16870-16875

[38] Klahr B, Gimenez S, Fabregat-Santiago F, Hamann T, Bisquert J. J Am Chem Soc. 2012 Mar 7;134(9):4294-302.

[39] Luca Bertoluzzi and Juan Bisquert, J. Phys. Chem. Lett. 2012, 3, 2517-2522

[40] Andreas Kay, Ilkay Cesar , and Michael Grätzel, J. Am. Chem. Soc., 2006, 128 (49), pp 15714-15721 
[41] D. Bora, A. Braun, R. Erni, G. Fortunato, T. Graule, E. Constable, Chem. Mater. 2011, 23, 2051-2061

[42] D.K. Bora, A.A. Rozhkova, K. Schrantz, P.P. Wyss, A. Braun, T. Graule, E.C. Constable, Advanced Functional Materials 2012, 22 (3) 490-502,

[43] Adams, M.W.W. and E.I. Stiefel, Current Opinion in Chemical Biology, 2000. 4: p. 214-220.

[44] Armstrong, F.A., Current Opinion in Chemical Biology, 2004. 8(2): p. 133-140.

[45] Gerrit van der Laan, Hitchhiker's Guide to Multiplet Calculations in "Magnetism: A Synchrotron Radiation Approach, Lecture Notes in Physics", 2006, Volume 697/2006, 143-199, DOI: 10.1007/3-540-33242-1_7

[46] F. M. F. de Groot, Chem. Rev. 101, 1779 (2001)

[47] S. Erat, A. Braun, A. Ovalle, C. Piamonteze, Z. Liu, T. Graule, and L. J. Gauckler, Appl. Phys. Lett. 95, 174108 (2009).

[48] Cramer, S.P., et al., Hyperfine Interactions, 2006. 170(1-3): p. 47-54.

[49] Xiao, Y., et al., J. Am. Chem. Soc., 2005. 127(42): p. 14596-14606.

[50] Guo, Y., et al., Inorganic Chemistry, 2008. 47(10): p. 3969-3977.

[51] Ogata, H., P. Kellers, and W. Lubitz, J. Molecular Biology, 2010. 402: 428-444.

[52] Bergmann, U., et al., J. Am. Chem. Soc., 2003. 125(14): p. 4016-4017.

[53] Pelmenschikov, V., et al., Faraday Discussions, 2010. 148: p. 409-420.

[54] J.-H. Guo, Y. Luo, A. Augustsson, S. Kashtanov, J.-E. Rubensson, D. K. Shuh, H. Ågren, J. Nordgren, Phys. Rev. Lett. 91, 157401-4 (2003)

[55] Lange, K.M.; Könnecke, R.; Soldatov, M.; Golnak, R.; Rubensson, J.-E.;

Soldatov, A.; Aziz, E.F. Angew. Chem. Int. Ed. 2011, 50, 1-6. 